\title{
Systematic investigation of the fatigue performance of a friction stir welded low alloy steel
}

\author{
Athanasios Toumpis $^{\mathrm{a} *}$, Alexander Galloway ${ }^{\mathrm{a}}$, Lars Molter ${ }^{\mathrm{b}}$, Helena Polezhayeva ${ }^{\mathrm{c}}$ \\ ${ }^{a}$ Department of Mechanical \& Aerospace Engineering, University of Strathclyde, James Weir Building, 75 \\ Montrose Street, Glasgow G1 1XJ, United Kingdom \\ ${ }^{b}$ Center of Maritime Technologies e.V., Bramfelder Str. 164, D-22305, Hamburg, Germany \\ 'Lloyd's Register EMEA, 71 Fenchurch Street, London EC3M 4BS, United Kingdom
}

\begin{abstract}
A comprehensive fatigue performance assessment of friction stir welded $\mathrm{DH} 36$ steel has been undertaken to address the relevant knowledge gap for this process on low alloy steel. A detailed set of experimental procedures specific to friction stir welding has been put forward, and the consequent study extensively examined the weld microstructure and hardness in support of the tensile and fatigue testing. The effect of varying welding parameters was also investigated. Microstructural observations have been correlated to the weldments' fatigue behaviour. The typical fatigue performance of friction stir welded steel plates has been established, exhibiting fatigue lives well above the weld detail class of the International Institute of Welding even for tests at $90 \%$ of yield strength, irrespective of minor instances of surface breaking flaws which have been identified. An understanding of the manner in which these flaws impact on the fatigue performance has been established, concluding that surface breaking irregularities such as these produced by the tool shoulder's features on the weld top surface can be the dominant factor for crack initiation under fatigue loading.
\end{abstract}

Keywords: Friction stir welding; Low alloy steel; Fatigue testing; Microstructural characterisation; Fracture surface analysis.

* Corresponding author. Tel.: +44 (0)141574 5075,

e-mail address: athanasios.toumpis@strath.ac.uk 


\section{Introduction}

There has been a growing number of studies demonstrating the feasibility of friction stir welding (FSW) of steel, producing defect-free welds, examining the microstructure and resultant mechanical properties of the welds, and concluding on the beneficial impact of this solid state joining process on the properties of welded steel components [1-8]. One representative publication [4] implements an extensive examination of FSW of DH36 steel in which an initial set of welding parameters that expand on the commonly applied welding speeds is developed through microstructural characterisation and mechanical property testing, and an understanding of the link between the complex metallurgical system that FSW of steel produces and the consequent mechanical properties is established; the higher strength and hardness of the welds is attributed to the greatly refined microstructure [4].

There remains however one important mechanical property of steel friction stir welds, fatigue, which requires to be investigated and reported. Fatigue of metals is a particularly significant property for numerous applications such as aerospace and marine [7], and is considered to be the most important failure mechanism for steels. It is commonly quoted for example that fatigue is responsible for almost $90 \%$ of all mechanical service failures [9]. In welded components, the weld itself contains process related flaws from which cracks can rapidly propagate. Thus, welding has been demonstrated as an undermining factor to the mechanical properties of such components; specifically under cyclic loading, welds are generally the dominant detail for fracture [10], also characterised as the critical design factor in shipbuilding [7]. In fusion welding, solidification cracking, i.e. minor inner cracks which can act as crack propagation sites during fatigue loads are considered unacceptable by international standards, hence need to be avoided [10]. Undercuts and lack of weld penetration are other examples of intolerable defects which are widely reported as highly detrimental features in terms of fatigue life [11]. Therefore, fatigue life of welded components is commonly much reduced when compared to components that are unwelded. The efforts in extending the fatigue life of components are primarily concentrated on improvements in design [12]. International rules have been developed to implement specifications in the design of structural details, thus reducing the applied stresses particularly by minimising possible stress concentration regions [13].

The research on FSW of aluminium and other low melting point metals is quite extensive, with the process achieving a level of maturity [6]. It has been demonstrated that FSW is a viable option for welding aluminium alloys, for example in automotive, rail and aerospace applications where welded components need to operate in extreme conditions therefore high fatigue strength is a fundamental requirement [14], also allowing for the successful joining of Al-alloys that cannot be welded with conventional fusion methods [15]. Many publications on FSW of aluminium examine the weldments' fatigue strength; indicatively, Ericsson and Sandstrom [16] investigate the effect of varying welding speed on the fatigue performance of friction stir butt welded high strength AI6082 and compare this to MIG and TIG fusion welding. The fatigue strength of FSW is found to be practically unaffected by speed increasing within the industrially acceptable range, and FSW exhibit higher fatigue lives than the two examined fusion welding methods in the same stress range [16]. Other studies assess the process's defect tolerance and fatigue behaviour with regard to the weld root flaw [17] and the post welding top surface finishing [14]. Kadlec et al. [17] evaluate the effect of the weld root flaw ("kissing bond") on the FSW fatigue performance of a high strength aluminium alloy and attempt a quantitative analysis concerning this flaw's length. A critical weld root flaw length of approx. $300 \mu \mathrm{m}$ is established; the welds' fatigue performance is seen to significantly decrease when a longer flaw is detected, hence becoming an unacceptable defect [17]. 
Although material property data are gradually being generated for FSW of high melting point alloys, the process has been slow to transfer to steel due to the more extreme conditions, mainly high flow stress and temperature, which are developed [6]. The relevant publications evaluating its behaviour in fatigue loading are very few [7] and seemingly small scale investigations. A comprehensive study [5] evaluating the technical potential of FSW as a shipbuilding welding process in comparison to submerged arc welding (SAW), a wellestablished technique in the shipbuilding sector, reports on an acicular shaped ferrite microstructure in the thermo-mechanically affected zone (TMAZ), consistent over the midthickness of all FSW samples, and a finer unspecified structure seemingly increasing with decreasing plate thickness. SAW samples present a typical acicular ferrite microstructure defined around proeutectoid ferrite grains. The study concludes that FSW of DH36 steel is feasible and moreover carries significant improvement in the mechanical properties of the welded components; specifically, the fatigue testing programme demonstrates that FSW samples exhibit better fatigue performance than the SAW samples of equivalent thickness. Impact toughness levels for FSW and SAW samples are noted to be similar and within classification society impact requirements. Further, analysis of the chemical composition of all welds reveals that SAW produces considerably different composition than the parent material (PM) due to the addition of filler material, while FSW results in no chemical segregation of the PM [5]. A further publication from the same research group compares double sided FSW of S275 structural steel in air and underwater in terms of the developed microstructure and resultant mechanical properties [6]. It is detailed that the TMAZ in both cases comprises refined ferrite grains produced by dynamic recrystallisation (DRX), smaller in air welding where slower cooling rate is expected, and dissociated pearlite. Fatigue testing (revealing comparable fatigue strength for air and underwater welds), tensile testing, and hardness measurements show that underwater FSW, an indispensable application for the marine sector, is not detrimental to the welds' mechanical properties apart from decreased impact toughness [6].

High quality welds of steel grade A36 are produced with pcBN and Tantalum-based FSW tools in a study assessing the mechanical properties and particularly the welds' fatigue performance with a focus on the shipbuilding sector [7]. Virtually no deterioration of the PM properties due to FSW is observed; tensile testing of the welds produced with the Ta-fabricated tool reveals higher yield strength (YS) than the corresponding of the pcBN tool. The fatigue lives of both groups of welds have not declined compared to the PM behaviour, with the Tantalum tool welded samples performing slightly better. The latter is attributed to the improved efficiency of this type of tool linked with suitably optimised welding parameters delivering an even hardness distribution throughout the weld zone [7]. On the relevant subject of fatigue crack growth rate, Pandey et al. [8] investigate friction stir butt welds of $3 \mathrm{~mm}$ thick mild steel. The weld YS is seen to be moderately increased compared to the PM but the elongation to fracture is reduced, due to the harder weld zone. It is concluded that the fatigue crack growth rates for FSW and $P M$ are almost identical when using stress ratio $(R)$ of 0.1 , whereas the PM crack growth rate is higher for $\mathrm{R}=0.2$ [8].

A study on the FSW of AISI 409M ferritic stainless steel researches the welds' fatigue behaviour with regard to the PM properties [18]. FSW is seen to transform the original coarse PM grains into a refined ferrite / martensite banded structure of significantly higher hardness. The resultant dual phase microstructure is responsible for an improvement in the fatigue life compared to the PM; notably, friction stir welded samples present higher fatigue lives than the base material and improved resistance to crack propagation [18]. Despite being quite comprehensive, the examination of only $300 \mathrm{~mm}$ long welds at a noticeably slow welding speed $(90 \mathrm{~mm} / \mathrm{min})$ weakens this study's merit. It is worthy of note that fusion welding reduces the 
desirable mechanical properties (ductility, toughness, etc.) of this alloy because of significant grain growth, whereas FSW can prevent these issues and achieve high quality welds by developing a highly refined microstructure; this represents an infrequently discussed positive effect of FSW [18].

Due to the significance of a solid understanding of the fatigue behaviour in supporting the acceptance of the process on steel within a wider industrial environment, the considerable potential of FSW in delivering high fatigue performance welds as concluded in the above discussed publications, and the lack of pertinent studies on low alloy steel, a detailed and extensive fatigue testing programme of steel grade DH36 FSW is undertaken. This original programme assesses the welds' fatigue behaviour by testing samples in constant amplitude uniaxial tensile loading, generating the S-N (stress-life) curve and comparing to international rules, also characterising the weld microstructure and analysing the fatigue samples' fracture surfaces; the experimental procedures and findings are reported herein.

\section{Experimental procedures}

There are no internationally accepted standards for the testing and assessment of welded components under fatigue [7], apart from guidelines. The lack of such standards is even more evident with regards to investigating the FSW of steel [18], a novel process. Thus, this study has formulated and observed a new standard operating procedure, i.e. a comprehensive set of guidelines for the fatigue assessment of FSW of steel. This allows for a fully compliant fatigue testing programme to be performed, and the various experimental stages are described below.

\subsection{Material and welding details}

The material under examination is steel grade $\mathrm{DH} 36$ with the nominal chemical composition presented in Table 1 (as supplied by the steel manufacturer). Steel plates with original dimensions of $2000 \mathrm{~mm} \times 200 \mathrm{~mm}$ and of $6 \mathrm{~mm}$ thickness were securely clamped on a PowerStir FSW machine without any prior surface preparation and butt welded together at varying traverse speeds to form a steel component of $2000 \mathrm{~mm} \times 400 \mathrm{~mm}$. The PowerStir welding machine is of a moving gantry type, has a large working bed and is extensively instrumented to allow for post process analysis of the welding parameters. Welding was performed in position control by employing a MegaStir Q70 pcBN-WRe hybrid tool for steel with scrolled shoulder (dia. $36.8 \mathrm{~mm}$ ) and stepped spiral probe $(5.7 \mathrm{~mm}$ length); the basic dimensions and geometry of the specific tool have been provided elsewhere [4]. The FSW tool is rotating anticlockwise with zero tilt, utilising a liquid cooling system and placed in an inert gas environment to protect it from high temperature oxidation. The welding parameters used in this study were selected as representative of the three welding speed groups which were investigated in a prior publication [4]; these are provided in Table 2.

\subsection{Sample preparation}

The position and sequence of all fatigue and tensile test samples with regard to the start of the weld was consistently marked before sectioning (Figure 1). The specific preparation stages adhered strictly to BS 7270 [19]. The samples' sides were polished longitudinally to diminish the contribution of any transverse machining marks to the fatigue performance, particularly from the parallel length, up to a surface finish of at least $0.2 \mu \mathrm{m} R_{a}$ [19]. To ensure that the required surface roughness was achieved, a large number of randomly chosen samples were 
validated using a Mitutoyo surface roughness measuring system. In contrast, the samples' top and bottom surfaces were tested in the "as-welded" condition. Fatigue and transverse tensile samples were prepared with the same basic dimensions, which are outlined in Figure 2.

The measurement of weld misalignments or other irregularities of the fatigue samples' geometry is an influential factor which is often overlooked in fatigue testing programmes. Clamping on the fatigue testing machine and consequent axial loading will certainly re-align a sample incorporating possible weld misalignment or distortion. This will induce tensile or compressive stresses on any surface breaking and even embedded flaws, hence accelerating or hindering any cracks which may initiate from these. For this purpose, contact scans of all samples top surface geometry were performed using a Mitutoyo coordinate measuring machine (CMM). More, strain gauges were installed on both sides of three fatigue samples for each stress range. The recorded $\mathrm{CMM}$ and strain gauge data revealed insignificant secondary bending due to axial or angular misalignment acting upon the samples during testing; few samples displayed maximum distortion of $0.72 \mathrm{~mm}$. Hence, the effect of possible weld misalignment on the fatigue performance was considered negligible.

\subsection{Metallographic examination and hardness measurements}

A detailed microstructural characterisation of the three welds was performed on an optical microscope in order to correlate their microstructure to the mechanical properties which are expected to exhibit, particularly their performance under fatigue, and to assess the quality of the welds by identifying possible flaws or defects induced by the FSW process. Metallographic samples were sectioned from the positions in between the fatigue samples for each weld. This allowed the examination of a particular section of the weld microstructure should the adjacent fatigue samples reveal an irregular behaviour, and provided a sufficient understanding of the microstructure along the entire length of each weld. The metallographic preparation of all samples was performed using standard met-prep equipment and in a way that the advancing (AD) side is seen on the left side of the images.

Micro-hardness measurements were recorded for several positions which were deemed representative of the weld zone, consistently for all three welds (Figure 3) to provide an understanding of the hardness distribution of the weld zones. The measurements were taken using a Mitutoyo hardness tester and by applying a load of $200 \mathrm{gf}$.

\subsection{Transverse tensile testing}

Three samples per weld were subjected to transverse tensile testing in order to identify the YS of the weldments. The trend reported elsewhere [1-6] was confirmed in this study; all slow and intermediate weld samples fractured in the PM, whereas the fast weld samples fractured in the $A D$ side of the weld. The average YS value from the three intermediate weld samples is 382 MPa (Table 3); this was used for calculating all welds' fatigue testing parameters to offer consistency and comparable results.

\subsection{Transverse fatigue testing}

As in the case of the above discussed tensile testing, fatigue testing was carried out on an Instron 8802 fatigue testing system. The number of tested samples per weld speed and stress range is provided in Table 4. Emphasis was placed on the intermediate welding speed, where more samples were tested and in three stress ranges to enhance the statistical validity of the recorded data. The selection of appropriate stress ranges was informed by trial tests which 
were initially performed, commencing with stress range of $80 \%$ of $Y S$. The effect of varying FSW parameters on the fatigue lives was established by testing samples from the slow and fast speed welds at one stress range and comparing these results with the basic S-N curve of the intermediate weld.

The calculated stress levels of all stress ranges which were used for programming the fatigue testing machine, principally mean stress and amplitude, are summarised in Table 5 . The stress ratio was maintained approx. equal to 0.1 and the stress frequency constant at $10 \mathrm{~Hz}$ during testing. The actual stresses attained by the testing machine vary insignificantly from the calculated values (no more than $0.1 \%$ ).

\section{Results and discussion}

\subsection{Microstructural characterisation}

The slow traverse speed weld $(100 \mathrm{~mm} / \mathrm{min}$ - $200 \mathrm{rpm})$ presents a ferrite predominant, homogeneous microstructure with significant grain refinement in comparison to the PM (Figure 4). The formation of highly refined ferrite grains has been reported previously whilst examining the FSW of steel grade E36 [3], a shipbuilding steel comparable to DH36 in terms of chemical composition and mechanical properties, and of a mild steel where it is associated with DRX [8]. The ferrite grains appear to be of random geometry, with minor traces of small acicular shaped grains (Figure 4). This observation is in good agreement with the findings on the slow welds discussed in an earlier work [4]. As expected for this mild set of welding parameters, no flaws are visible in the bulk of the TMAZ, the transition from the heat affected zone (HAZ) to the TMAZ is smooth (Figure 5a showing the retreating (RT) side), and the non-metallic inclusions introduced in the weld from the plates' surfaces are not completely mixed but remain interconnected. The weld's top surface appears slightly uneven but gradually improving towards the end of the weld. Both sides of the top surface present signs of non-metallic inclusions interconnected in incomplete fusion regions, however insignificant in size Figure 5b).

A heterogeneous microstructure is exhibited by the weld at $250 \mathrm{~mm} / \mathrm{min}-300 \mathrm{rpm}$ (intermediate traverse speed); this consists of acicular shaped bainitic ferrite rich regions and ferrite predominant regions of either acicular shape or of random geometry (Figure $6 a \& 6 b$ ). Prior austenite grain boundaries are faintly observable in the bainite rich areas of the TMAZ (Figure 6b). The resultant acicular ferrite and acicular bainitic ferrite phases have been disclosed in previous studies on the same grade of steel [5] and for identical welding parameters [4]. The microstructure differs towards the bottom and outer sides of the weld, shifting to predominantly refined ferrite grains of random geometry (Figure 6c). This image also features a non-metallic inclusion which appears to have created a discontinuity in the surrounding phase, i.e. a cavity.

The top surface of the intermediate weld is mildly uneven, indented by the tool shoulder's threads. There is a small number of incomplete fusion paths, or laps [20] observed particularly on the outer top RT side (Figure 7), with entrapped and interconnected non-metallic inclusions in various stages of oxidation (seen in different shades of grey). These laps are seen to provide crack initiation sites during fatigue testing (see section 3.3). The weld root has been fully fused, and the microstructure of this region comprises recrystallized ferrite and pearlite. There has been no substantial mechanical stirring of the steel in this area; therefore, the driving force for the transformation (DRX in this case) is the thermal energy which has dissipated from the bulk 
of the weld. More, there is strong indication of a recurrent region of insufficient fusion, also labelled cold shut [20], observed at the mid-AD side of the intermediate weld (Figure 8).

A particular characteristic of one of the examined samples from the intermediate speed weld is worthy of note. There is one material flow line in the outer top $A D$ side with a microstructure very distinct from the surrounding regions (Figure 9a). This is a predominantly ferrite phase of refined and equiaxed grains inside the previously discussed acicular bainitic ferrite and acicular ferrite of the TMAZ (Figure 9b). Thus, this particularly heterogeneous area may have been formed by metal having been transported from another region (perhaps the outer bottom side where a slower cooling rate occurred) due to the powerful stirring action of the tool during FSW.

The fast traverse speed weld $(500 \mathrm{~mm} / \mathrm{min}-700 \mathrm{rpm})$ features what seems to be a heterogeneous but predominantly acicular shaped bainitic ferrite microstructure with small regions of acicula ferrite (Figure 10); this microstructure is identical to the one described previously [4]. The increased bainitic content is a direct consequence of the higher cooling rate due to the higher traverse speed of this weld. More, prior austenite grain boundaries are clearly detected (Figure 10); acicular shaped grains appear to nucleate perpendicular to these boundaries. Earlier studies in the FSW of steel [1] noted bainitic and martensitic phases in DH36 for comparable welding speeds; increased knowledge on steel FSW has led to recent studies achieving martensite-free welds [7].

The weld demonstrates a poor quality top surface with marks on both sides corresponding to the tool shoulder's features (Figure 11a), and laps introducing non-metallic inclusions in the TMAZ which appear in post-weld oxidation (Figure 11b); again, these are stress concentration regions which are expected to provide crack initiation sites hence influence the weld's fatigue performance. Similar poor top surface with fissures is seen on the HSLA-65 shipbuilding steel welds of an earlier publication [2] and confirmed by optical microscopy. Konkol et al. attribute this process related flaw to the tool shoulder and clarify that it could compromise the weld's fatigue performance [2].

The FSW tool appears to have deviated slightly off centre as it traverses through the original plate interface developing evidently intermittent insufficient fusion at the weld root, i.e. a weld root flaw (Figure 12a). Since there is almost no stirring action of the tool's probe on the steel in this region of reduced temperature, the thin film of non-metallic inclusions on the surface of the two plates being welded is not fully dispersed, thus forming a joint line remnant as an extension of the weld root flaw (Figure 12a). For the same reason of minimal mechanical deformation, the microstructure of this region is very different from the bulk of the weld (TMAZ). This consists of highly refined, almost equiaxed ferrite grains, where the prior ferrite / pearlite PM grain structure is still barely visible (Figure 12b). This transformation is primarily attributed to the thermal energy dissipating towards the bottom of the plate. The boundary between HAZ and TMAZ on the mid-AD side of the weld contains few entrapped non-metallic inclusions which have not allowed the material to flow properly during welding, hence producing small cavities, or cold shuts, around them. Still, it is anticipated that such flow-related embedded flaws will not be detrimental to the weld's behaviour under fatigue.

\subsubsection{Hardness distribution}

The micro-hardness measurements for the three welds are presented in Table 6, where the values are supplied as an average of two measurements per position marked in Figure 3 (two samples measured in the intermediate speed). The hardness values follow the anticipated order; the hardness of the weld is seen to increase as the welding speed is increased. This is attributed to the increasing cooling rate which develops harder phases such as bainite. The 
microstructural examination above has noted the rise in the bainite content with each speed increment. Broadly, all welds appear harder than the PM but not at levels that can cause concern. The gradual increase from PM hardness to a peak in the middle of the TMAZ is also identified by Azevedo et al. [7] using the same type of FSW tool for steel and similar welding speeds (slow and fast). Pandey et al. [8] record smaller increase in the TMAZ hardness compared to the PM; this can be attributed to the application of very slow welding speed ( 80 $\mathrm{mm} / \mathrm{min}$ ) for the given rotational speed $(700 \mathrm{rpm})$ which develops lower cooling rates.

\subsection{Fatigue assessment}

The experimental S-N data of the intermediate $(250 \mathrm{~mm} / \mathrm{min})$ speed samples for the three stress ranges are plotted as fatigue life (in number of cycles to fracture) vs. nominal stress range value for each sample $(\Delta \sigma$, in $\mathrm{MPa})$ in double logarithmic scale (Figure 13$)$. The ultimate fracture position for 24 out of the 25 tested samples of the intermediate weld was the weld's RT side (Figure 14). The fracture initiation sites are pinpointed as the lap defects observed on this side's top surface; minor embedded flaws detected on the AD side did not offer crack initiation sites (see section 3.3). In addition, the transverse tensile samples of the same weld fracturing in the PM substantiates that, except for the yield strength, static loading does not carry important information on the material's performance in real environments where cyclic loading is the dominant stress mechanism.

The original objective of this investigation had been the recording of fatigue lives within the range of $10^{5}$ to $2.5^{*} 10^{6}$ cycles. This testing programme reveals an excellent picture of FSW of low alloy steel, with all tests reaching well above $10^{5}$ cycles. One intermediate weld test was terminated before fracture since it reached a number of cycles $\left(2.6^{*} 10^{6}\right)$ far above the predetermined objective. The surface breaking flaws appeared to be less pronounced in this region of the weld, thus no fracture occurred within the duration of this particular test.

The fatigue test results for the slow and fast welds at $80 \%$ of $Y S$ are plotted in Figure 15 together with the intermediate weld results of the same stress range for comparison. Two samples of the slow $(100 \mathrm{~mm} / \mathrm{min})$ weld exhibited excellent fatigue behaviour; the tests were terminated at $2.5^{*} 10^{6}$ cycles without fracture. One sample fractured prematurely at $4.2^{*} 10^{5}$ cycles (although higher than the lower limit of cycles that was set) on the AD side of the weld, and this is attributed to the incomplete fusion paths observed in this section of the weld (see section 3.3). The fast $(500 \mathrm{~mm} / \mathrm{min})$ weld samples demonstrated a rather mixed fatigue behaviour; all three samples recorded fatigue lives higher than $10^{5}$ cycles but with some scatter of the results, from $2.2^{*} 10^{5}$ to $7.2^{*} 10^{5}$, and contrasting fracture regions. The varying intensity of the flaws observed in this weld is primarily responsible for this phenomenon. Fracture initiated for two samples from the weld root flaw which has been documented earlier (Figure 12). The fracture initiation region on the third sample corresponds to the lap defects seen in Figure 11b. Table 7 outlines the fracture location of each welding speed sample that was tested in fatigue loading.

\subsubsection{Comparison to IIW Recommendations}

In order to understand the relevance of the above reported results, mainly for the intermediate weld, these need to be placed in the context of international regulations and specifications. In the maritime sector for instance, the fatigue performance of welded joints is of critical importance as components are subjected to repeated cyclic loading conditions [7]. Most pertinent class society rules are based on the recommendations of the International Institute of Welding (IIW) for fusion welds [21]. A series of design related fatigue classes (FAT classes) 
have been established to ensure safe operation of the welded joints during their effective service life and enable the streamlined and reliable design of welded structural details. The FAT classes define the cyclic stress range that will not result in fracture within $2^{*} 10^{6}$ cycles at a $97.7 \%$ probability for various structural details (e.g. butt welding in flat position with backing strip). All values within these FAT classes are based on experimental data and refer to certain boundary conditions, specifically weld geometry, defect limits and material properties (e.g. hardness) that are stated in the IIW recommendations [21] and class society rules. Although seemingly different from conventional fusion welds in weld geometry and metallurgical features, the fatigue loading mechanism and related design aspects of friction stir butt welds are essentially equivalent. Thus, FSW needs to be initially evaluated and compared to the established class rules for fusion welding for the process to be introduced in marine applications.

Figure 16 displays the S-N curve for the intermediate speed weld; the slope of the curve is $\mathrm{m}=3$ according to the IIW recommendations. The dotted lines represent the probability of survival at $97.7 \%, 50.0 \%$ (mean) and $2.3 \%$. The solid line indicates the IIW FAT 80 weld detail class for single sided butt welded joints at $97.7 \%$ probability of survival (detail No. 214 in Ref.21). The fatigue strength of the FAT 80 class at $2 * 10^{6}$ cycles where the samples' fatigue strength is evaluated is $80 \mathrm{MPa}$ for $97.7 \%$ probability of survival. The results demonstrate higher fatigue strength for all samples of the intermediate weld in comparison to the FAT 80 class. The FSW samples' fatigue strength is calculated at $125 \mathrm{MPa}$ (for $97.7 \%$ probability of survival); this is $56 \%$ higher than the strength stated in the IIW recommendations. Since no standards for assessing the fatigue behaviour of steel FSW exist, analogous comparison to IIWrecommended fatigue design classes is employed by one more publication, in which the FSW fatigue data are contrasted to the FAT 112 class [18]. The examined welds' fatigue performance is higher than this class, which is the most demanding in fusion welding of steel [18].

Figure 17 provides a point of reference for the intermediate FSW fatigue test results when compared to the results of high quality laser welded butt joints $(3 \mathrm{~mm}$ thick DH36 welds in transverse cyclic loading at $10 \mathrm{~Hz}$ ) generated in a prior investigation [22]. Both sets of results display similar fatigue strengths for comparable stress ranges; in fact, FSW appear to produce marginally longer fatigue lives at the highest stress range. As a general note, the fatigue performance of the tested samples illustrates a considerable potential of steel FSW; the welds show better overall fatigue strength in comparison to the IIW recommendations and comparable to laser welding, irrespective of any minor surface breaking and embedded flaws that were detected.

\subsubsection{Lap defect removal}

Microstructural observations and subsequent measurements on the captured micrographs (Figure 7) with suitable software have shown that the deepest top surface lap defect found in the intermediate speed weld is approx. $0.45 \mathrm{~mm}$. Since this defect has been the decisive factor in fracture initiation, it is fitting to assess the weld's fatigue behaviour should this process related feature had been avoided. For this purpose, three fatigue tests were performed at a stress range of $90 \%$ of YS employing intermediate weld samples from which the top $0.5 \mathrm{~mm}$ had been removed by grinding and polishing. The three tests were terminated at $3.2^{*} 10^{6}$ cycles or above; the samples revealed no discernible evidence of fracture initiation features after these tests.

The additional samples' fatigue lives are plotted with two standard fatigue samples also tested at $90 \%$ of YS, and sectioned from neighbouring (to the additional) sites of the intermediate weld 
(Figure 18). The supplementary samples with the top $0.5 \mathrm{~mm}$ removed are seen to substantially outperform the standard fatigue samples for the same stress range. This comparison offers further confirmation of a substantial improvement in fatigue life by the simple removal of the lap defect and an indication of the potentially impressive fatigue performance of the process when an acceptable quality weld (specifically, without surface breaking defects) has been achieved. A comparable approach has been followed by a separate study evaluating the influence of the post welding top surface condition on the fatigue performance of friction stir butt welded AA8090 [14]. As-welded samples are tested opposite to top surface treated ones by grinding which removed any weld irregularities. The surface treated samples reveal higher fatigue lives than the corresponding as-welded, principally for lower stress ranges; fracture is found to initiate for the former in the PM or HAZ whereas for the latter in the weld nugget. Thus, the research concludes that post weld surface finishing can offer clear improvement to the fatigue behaviour because it eliminates process related flaws which serve as crack initiation sites [14].

\subsection{Fracture surface analysis}

Post-failure fracture surface analysis of all samples tested in fatigue loading is performed to provide information on the crack initiation sites, the crack propagation paths and the mode of fracture. A recurrent pattern of fracture is observed in the intermediate weld samples; principally brittle fracture occurred on the outer RT side, with cracks initiating from this side's lap defects. For reporting purposes, two samples' typical fracture surfaces are presented herein as all the surfaces appear almost identical. Figure 19 features the two extreme cases in terms of number of cycles to fracture (lowest and highest) for the intermediate group tested at $80 \%$ of YS in order to enhance the fine differences from one sample to another. Figure 19a presents the sample that reached 317,472 cycles to fracture; uniform crack initiation from multiple sites corresponding to the FSW tool shoulder's markings on the weld's top surface is indicated with the arrows. Each of these sites includes many secondary which are seen as light of dark shaded hairline cracks. As a result, many cracks propagate faster through the sample leading to reduced number of cycles hence poorer fatigue performance. The other extreme, a sample from the same weld and fatigue testing group with 1,967,444 cycles until fracture is observed in Figure 19b; here, crack initiation concentrated in one site. Fewer secondary hairline cracks appear to initiate from this area. Therefore, such localised crack initiation will take significantly longer to propagate through the entire cross-section of the sample. In contrast, the minor embedded flaw (cold shut) which has been mentioned in section 3.1 as seen principally in the $A D$ side of the weld did not contribute in the fracture behaviour of the fatigue samples.

The typical shape of a friction stir butt weld is curved towards the bottom surface of the two welded plates (e.g. macrograph of Figure 9). The fracture plane of all fatigue samples is practically perpendicular to the weld top surface (Figure 20). Thus, cracks have initiated at the outer RT side of the top surface (lap defect upper "lip" marked in Figure 20), propagated for a short part of the cross-section in the outer TMAZ and then advanced in the PM. The highly refined microstructure of the weld has diverted the crack propagation path away from the weld zone and into the PM. Consequently, the bottom layer of all samples fracture surfaces (both samples in Figure 19), the final fracture region [17], is the PM which exhibits mainly ductile fracture as anticipated. Furthermore, examination of the regions which appear to be better welded thus exhibiting ductile fracture (right side regions of both samples' fracture surfaces in Figure 19) reveals similar crack initiation sites on the top surface. The lap defect is observed continuously along the weld length but with varying intensity and depth. Therefore, some weld 
regions (e.g. these marked with arrows where the lap defect is more pronounced) have been more convenient in developing initiated cracks than others.

In the case of one slow speed weld sample which actually fractured, the crack initiation sites appear to be originating from incomplete fusion paths on the AD side (Figure 21). These paths which have formed in the direction of material flow contain interconnected non-metallic inclusions, and are quite steep; hence excessive concentration of stresses must have been present. The fracture surfaces of this sample are identical to the surfaces of the intermediate weld samples (Figure 19a).

Similarly to the intermediate samples above, the two fast weld samples where cracks initiated from the weld root flaw display a fracture plane perpendicular to the plate thickness and fracture surfaces comparable to Figure 19a. The crack propagated in the middle of the weld, almost exactly in the path of the original plate interface (Figure 22). The importance of the weld root flaw as a limiting factor in the fatigue performance of FSW and the difficulties in eradicating it have been established in prior studies $[14,17]$. The third sample however reveals fracture surfaces identical to one of the high speed welds' samples discussed in an earlier publication [4]. It was then argued that these surfaces are product of the FSW tool probe's features, indication that lower than required heat input was provided in this region, leading to insufficient plasticisation of the metal which was ultimately mechanically worked rather than thermomechanically stirred by the tool [4]; this description is fitting in illustrating this sample's fracture surfaces (Figure 23). The same figure offers evidence of uniform crack initiation from the tool shoulder's markings on the weld top surface (indicated on Figure 23).

\section{Conclusions}

A fully developed programme of fatigue performance assessment of $6 \mathrm{~mm}$ thick DH36 steel friction stir butt welds has been undertaken by adopting a comprehensive set of experimental procedures to build on the fundamental knowledge on the process and address the lack of relevant studies for fatigue testing of friction stir welded low alloy steel. This has examined the weld microstructure, hardness distribution, geometry and possible misalignments, tensile properties and fatigue behaviour, also accounting for the effect of varying welding speed. The following conclusions have been drawn from this testing programme:

- Friction stir welds of steel grade DH36 exhibit satisfactory fatigue lives, even at a stress range of $90 \%$ of yield strength, above the weld detail class of the International Institute of Welding for single side fusion welded butt joints.

- High or very high fatigue lives were recorded for three stress ranges, regardless of any minor surface breaking flaws developed in the intermediate weld, therefore displaying excellent fatigue performance (better than international recommendations and equal to high quality laser welding).

- The slow welding speed which produces a highly refined, homogeneous and free of embedded flaws microstructure demonstrates the best fatigue performance of the three welding speeds which have been investigated.

- The fatigue strength of the high speed weld samples is reduced to a certain degree compared to the two slower welds; still, the weld achieved fatigue lives above $10^{5}$ cycles and this is anticipated to improve dramatically when various process related flaws are addressed. 
- An understanding of the relationship between weld flaws and their influence on the fatigue performance has been established; microstructural examination, post testing fracture surface analysis identifying consistent fracture position and the complementary assessment of samples without top surface defects have demonstrated that minor embedded flaws do not offer crack initiation sites whilst surface breaking flaws such as the markings produced by the FSW tool shoulder's features on the top surface of the weld deliver a significant impact on the fatigue life.

- The lap defects need to be tackled by optimisation of the process parameters and improvements in the design and materials of the FSW tool for steel.

- This investigation further justifies the need for full penetration welds and to carefully address the tool shoulder's markings which in many cases serve as the critical fracture initiation site in the absence of a weld root flaw.

\section{Acknowledgements}

The authors gratefully acknowledge the financial support of the European Union which has funded this work as part of the Collaborative Research Project HILDA (High Integrity Low Distortion Assembly) through the Seventh Framework Programme (SCP2-GA-2012-314534HILDA).

\section{References}

[1] Reynolds AP, Tang W, Posada M, Deloach J. Friction stir welding of DH36 steel. Sci Technol Weld Join 2003;8:455-60.

[2] Konkol P, Mathers J, Johnson R, Pickens JR. Friction stir welding of HSLA-65 steel for shipbuilding. J Sh Prod 2003;19:159-64.

[3] Cater S, Martin J, Galloway A, Mcpherson N. Comparison between friction stir and submerged arc welding applied to joining DH36 and E36 shipbuilding steel. In: Mishra R, Mahoney MW, Sato Y, Hovanski Y, Verma R, editors. Frict. Stir Weld. Process. VII, New Jersey: Wiley; 2013, p. 49-58.

[4] Toumpis A, Galloway A, Cater S, McPherson N. Development of a process envelope for friction stir welding of DH36 steel - A step change. Mater Des 2014;62:64-75.

[5] McPherson NA, Galloway AM, Cater SR, Hambling SJ. Friction stir welding of thin DH36 steel plate. Sci Technol Weld Join 2013;18:441-50.

[6] Baillie P, Campbell S, Galloway A, Cater S, Mcpherson N. A Comparison of Double Sided Friction Stir Welding in Air and Underwater for 6mm S275 Steel Plate. Int J Chem Nucl Metall Mater Eng 2014;8:651-5.

[7] Azevedo J, Infante V, Quintino L, dos Santos J. Fatigue Behaviour of Friction Stir Welded Steel Joints. Adv Mater Res 2014;891-892:1488-93.

[8] Pandey K, Gupta S. Fatigue Crack Growth Analysis of Mild Steel Plate Welded by Friction Stir Welding. ASME 2013 Int. Mech. Eng. Congr. Expo., San Diego, CA: ASME; 2013, p. V009T10A013. 
[9] Campbell F, editor. Elements of Metallurgy and Engineering Alloys. Materials Park, $\mathrm{OH}$ : ASM International; 2008.

[10] Schaumann P, Collmann M. Influence of Weld Defects on the Fatigue Resistance of Thick Steel Plates. Procedia Eng 2013;66:62-72.

[11] Maddox SJ. Fatigue Strength of Welded Structures. 2nd ed. Cambridge: Woodhead Publishing; 2002.

[12] Kirkhope K, Bell R, Caron L, Basu R, Ma K-T. Weld detail fatigue life improvement techniques. Part 1: review. Mar Struct 1999;12:447-74.

[13] Pilkey W. Formulas for Stress, Strain, and Structural Matrices. 2nd ed. Hoboken, NJ: Wiley; 2005.

[14] Pedemonte M, Gambaro C, Lertora E, Mandolfino C. Fatigue assessment of AA 8090 friction stir butt welds after surface finishing treatment. Aerosp Sci Technol 2013;27:18892.

[15] Gungor B, Kaluc E, Taban E, Sik A. Mechanical, fatigue and microstructural properties of friction stir welded 5083-H111 and 6082-T651 aluminum alloys. Mater Des 2014;56:8490.

[16] Ericsson M, Sandstrom R. Influence of welding speed on the fatigue of friction stir welds, and comparison with MIG and TIG. Int J Fatigue 2003;25:1379-87.

[17] Kadlec M, Růžek R, Nováková L. Influence of the Kissing Bond Defect to the Fatigue Life in Friction Stir Welds of 7475 Aluminium Alloy. 10th Int. Frict. Stir Weld. Symp., Beijing, China: 2014.

[18] Lakshminarayanan AK, Balasubramanian V. Assessment of fatigue life and crack growth resistance of friction stir welded AISI 409M ferritic stainless steel joints. Mater Sci Eng A 2012;539:143-53.

[19] British Standards Institution. Metallic materials - Constant amplitude strain controlled axial fatigue - Method of test. BS 7270. London; 2006.

[20] Becker W, Shipley R, editors. ASM Handbook Volume 11: Failure Analysis and Prevention. Materials Park, OH: ASM International; 2002.

[21] Hobbacher A. Recommendations for Fatigue Design of Welded Joints and Components. International Institute of Welding, doc. IIW-1823-07. Paris; 2008.

[22] Collaborative Research Project BESST (Breakthrough in European Ship and Shipbuilding Technologies), E.U. Seventh Framework Programme (FP7/2007-2013), grant agreement 233980 . 


\section{Table captions}

Table 1. Chemical composition of $6 \mathrm{~mm}$ thick DH36 steel (wt\%).

Table 2. FSW parameters employed in this testing programme.

Table 3. Summary of transverse tensile test results for FSW of intermediate speed group.

Table 4. Number of tested fatigue samples per welding speed.

Table 5. Summary of the fatigue testing nominal stresses.

Table 6. Micro-hardness (Vickers) measurements for the three weld speeds.

Table 7. Fracture location of each welding speed sample (AD side on the left).

\section{Figure captions}

Figure 1. Schematic of the samples' position on a FSW; $F_{x}$ : fatigue sample, $M_{x}$ : metallography sample.

Figure 2. Transverse fatigue and tensile test sample of rectangular cross section (thickness 6 $\mathrm{mm})$.

Figure 3. Typical FSW macrograph with the positions of hardness measurements.

Figure 4. Slow weld, microstructure of mid-TMAZ [x1000, Etched].

Figure 5. Slow weld: (a) transition from HAZ to TMAZ, RT side [x50, Etched]; (b) top surface, RT side [x500, Etched].

Figure 6. Intermediate weld [x1000, Etched]: (a) \& (b) microstructure of mid-TMAZ; (c) microstructure of outer AD TMAZ.

Figure 7. Intermediate weld, RT side top surface: (a) [x100, Etched]; (b) [x500, Etched].

Figure 8. Intermediate weld, AD side [x500, Etched].

Figure 9. Intermediate weld, top AD side: (a) [x50, Etched]; (b) [x500, Etched].

Figure 10. Fast weld, microstructure of mid-TMAZ [x1000, Etched].

Figure 11. Fast weld, top surface: (a) RT side [x50, Etched]; (b) AD side [x500, Etched].

Figure 12. Fast weld, root: (a) [x50, Etched]; (b) [x500, Etched].

Figure 13. S-N data for the intermediate weld.

Figure 14. Typical fracture position of intermediate weld sample.

Figure 15. Fatigue test results for 3 welding speeds at $80 \%$ of $Y S$.

Figure 16. S-N curve of the three welds compared to the IIW FAT 80 class.

Figure 17. Intermediate weld fatigue test results vs. laser welding and FAT 80 class.

Figure 18. Additional tests with samples' top $0.5 \mathrm{~mm}$ removed vs. two standard tests.

Figure 19. Intermediate weld samples tested at $80 \%$ of YS: (a) 317,472 cycles; (b) $1,967,444$ cycles. 
Figure 20. Macrograph of intermediate weld sample's fracture path (side view) [Etched].

Figure 21. Slow weld, AD side top surface: (a) [x500, Etched]; (b) [x1000, Etched].

Figure 22. Macrograph of fast weld sample's fracture path (side view) [Etched].

Figure 23. Fast weld sample tested at $80 \%$ of YS $(222,272$ cycles to fracture).

\section{Tables}

Table 1. Chemical composition of $6 \mathrm{~mm}$ thick DH36 steel (wt\%).

\begin{tabular}{cccccccc}
\hline $\mathrm{C}$ & $\mathrm{Si}$ & $\mathrm{Mn}$ & $\mathrm{P}$ & $\mathrm{S}$ & $\mathrm{Al}$ & $\mathrm{Nb}$ & $\mathrm{N}$ \\
\hline 0.11 & 0.37 & 1.48 & 0.014 & 0.004 & 0.02 & 0.02 & 0.002 \\
\hline
\end{tabular}

Table 2. FSW parameters employed in this testing programme.

\begin{tabular}{lccc}
\hline Welding speed group & Slow & Intermediate & Fast \\
\hline Traverse speed $(\mathrm{mm} / \mathrm{min})$ & 100 & 250 & 500 \\
\hline Rotational speed $(\mathrm{rpm})$ & 200 & 300 & 700 \\
\hline
\end{tabular}

Table 3. Summary of transverse tensile test results for FSW of intermediate speed group.

\begin{tabular}{|c|c|c|c|c|c|}
\hline $\begin{array}{l}\text { Tensile } \\
\text { sample }\end{array}$ & $\begin{array}{l}\text { Traverse speed } \\
\qquad(\mathrm{mm} / \mathrm{min})\end{array}$ & $\begin{array}{c}\text { Rotational } \\
\text { speed (rpm) }\end{array}$ & $\begin{array}{c}\text { Yield Strength, } \\
0.2 \%(\mathrm{MPa})\end{array}$ & $\begin{array}{l}\text { Region of } \\
\text { fracture }\end{array}$ & $\begin{array}{c}\text { Fracture } \\
\text { mode }\end{array}$ \\
\hline Inter-1 & & & 385 & PM & Ductile \\
\hline Inter-2 & 250 & 300 & 382 & PM & Ductile \\
\hline Inter-3 & & & 378 & PM & Ductile \\
\hline \multicolumn{3}{|c|}{ Average yield strength } & 382 & & \\
\hline
\end{tabular}


Table 4. Number of tested fatigue samples per welding speed.

\begin{tabular}{ccc}
\hline Welding speed & $\begin{array}{c}\text { Stress range } \\
\text { (\% of YS })\end{array}$ & $\begin{array}{c}\text { Number of tested } \\
\text { samples }\end{array}$ \\
\cline { 2 - 3 } Intermediate & 90 & 10 \\
\cline { 2 - 3 } & 80 & 10 \\
\hline Slow & 70 & 5 \\
\hline Fast & 80 & 3 \\
\hline
\end{tabular}

Table 5. Summary of the fatigue testing nominal stresses.

\begin{tabular}{cccccc}
\hline \multirow{2}{*}{$\begin{array}{c}\text { Welding } \\
\text { speed }\end{array}$} & $\begin{array}{c}\text { Stress } \\
\text { range }\end{array}$ & $\begin{array}{c}\text { Maximum } \\
\text { stress }\end{array}$ & $\begin{array}{c}\text { Minimum } \\
\text { stress }\end{array}$ & $\begin{array}{c}\text { Mean } \\
\text { stress }\end{array}$ & Amplitude \\
\cline { 2 - 6 } & $\%$ of YS & $\sigma_{\max }(\mathrm{MPa})$ & $\sigma_{\min }(\mathrm{MPa})$ & $\sigma_{\mathrm{m}}(\mathrm{MPa})$ & $\sigma_{\mathrm{a}}(\mathrm{MPa})$ \\
\hline \multirow{2}{*}{ Intermediate } & 90 & 343.80 & 34.38 & 189.09 & 154.71 \\
\cline { 2 - 6 } & 70 & 305.60 & 30.56 & 168.08 & 137.52 \\
\cline { 2 - 6 } & 80 & 305.60 & 30.56 & 168.08 & 137.52 \\
\hline Slow & 80 & 305.60 & 30.56 & 168.08 & 137.52 \\
\hline Fast & 80 & & & & 120.33 \\
\hline
\end{tabular}

Table 6. Micro-hardness (Vickers) measurements for the three welding speeds.

\begin{tabular}{lcccccccc}
\hline Weld & AD top & Mid-top & RT top & Mid-AD & Mid-TMAZ & Mid-RT & Weld root & PM \\
\hline Slow & 225 & 247 & 244 & 230 & 226 & 222 & 225 & 189 \\
\hline Inter-1 & 302 & 257 & 247 & 266 & 265 & 247 & 240 & 169 \\
\hline Inter-2 & 316 & 241 & 254 & 259 & 279 & 233 & 254 & 191 \\
\hline Fast & 320 & 303 & 318 & 306 & 355 & 356 & 250 & 184 \\
\hline
\end{tabular}


Table 7. Fracture location of each welding speed sample (AD side on the left).

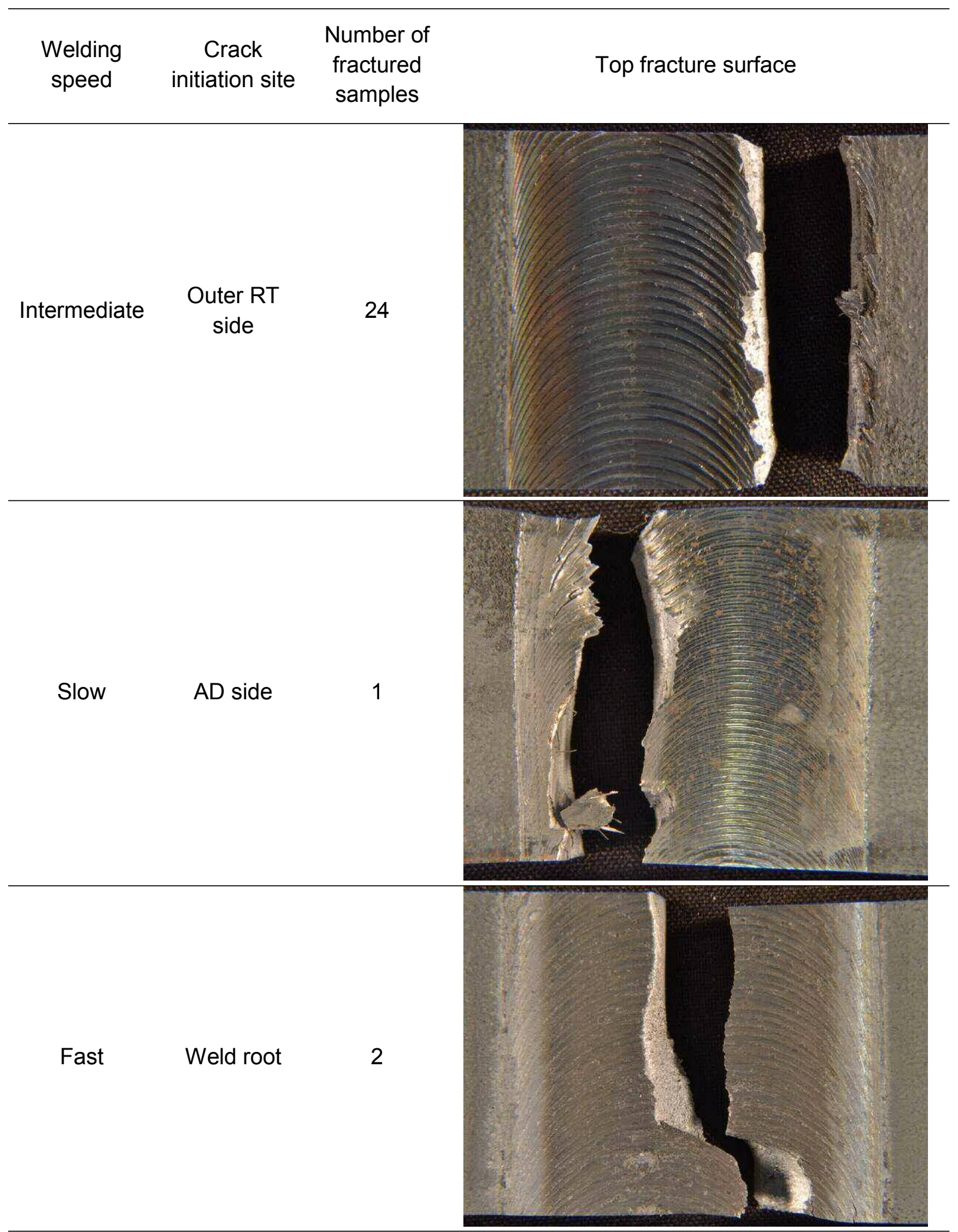




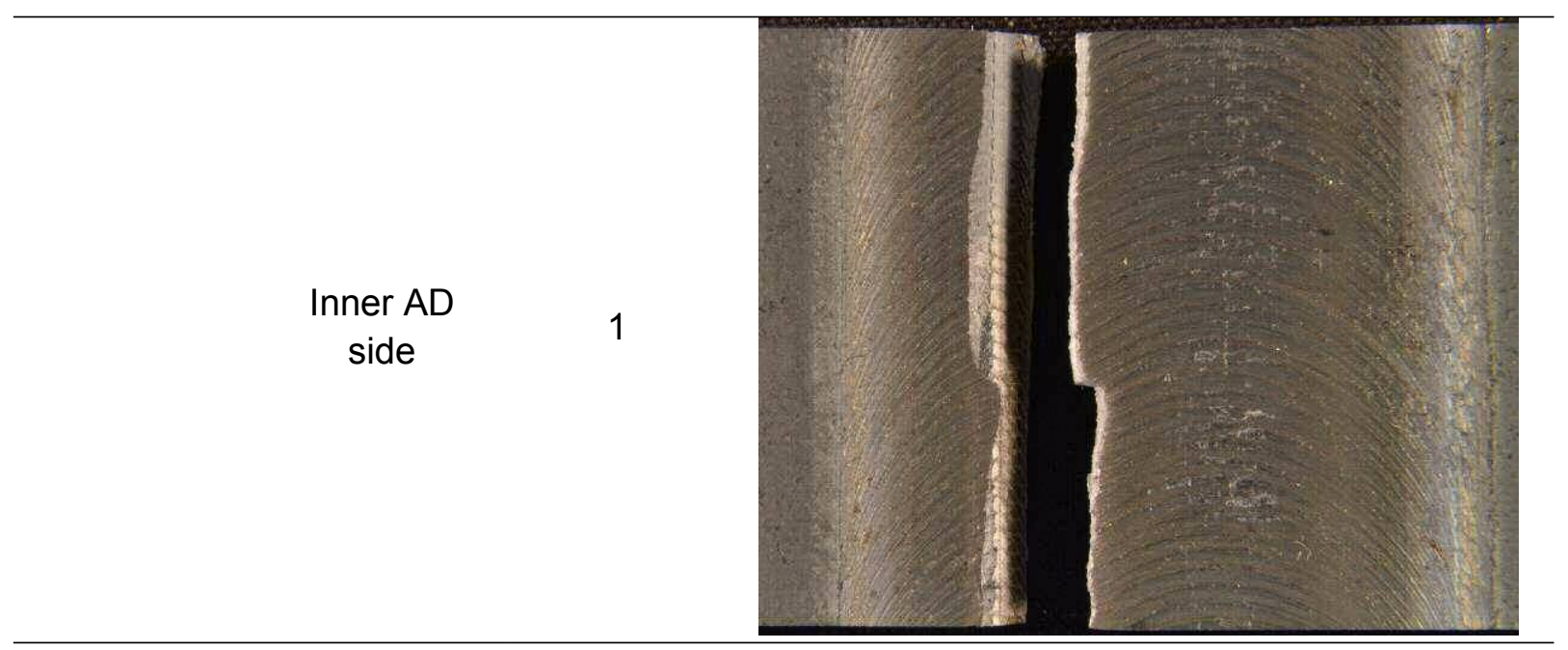




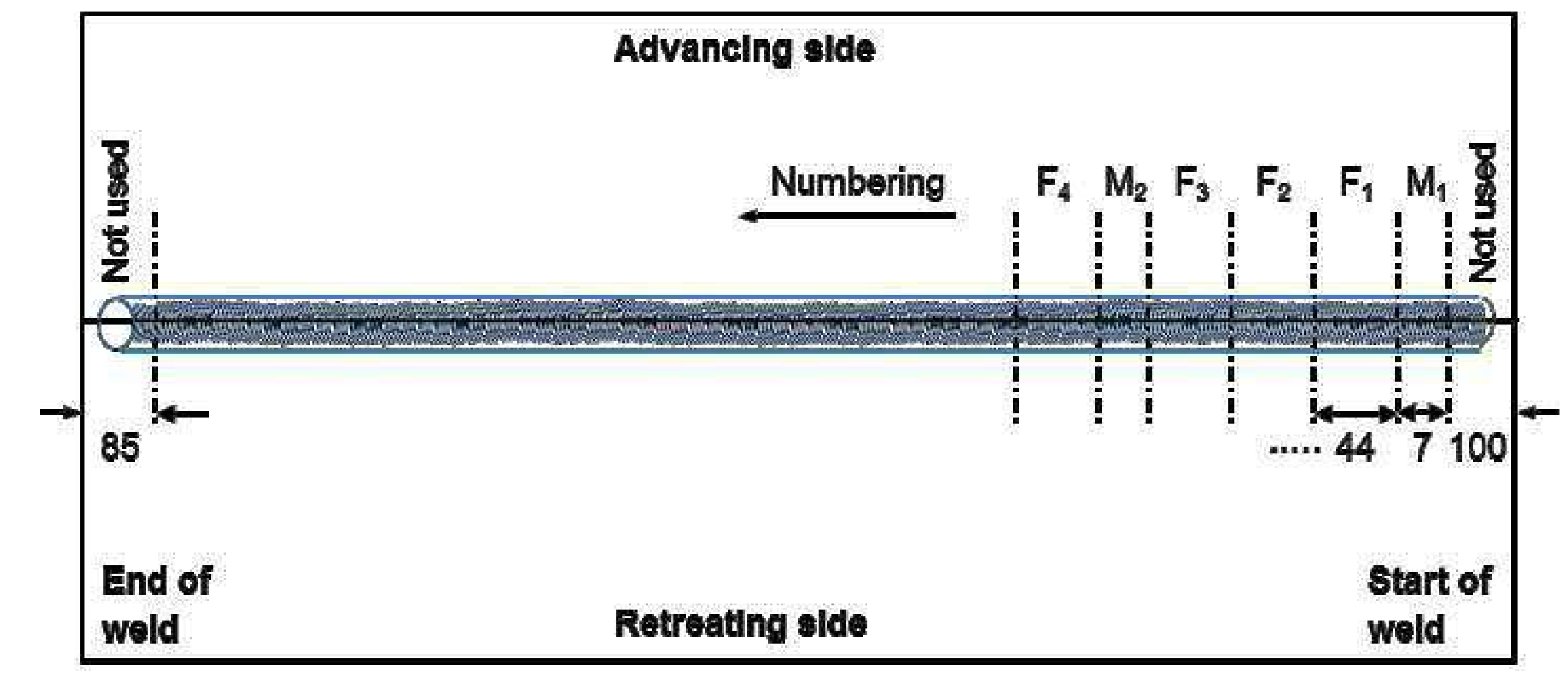


Click here to download high resolution image

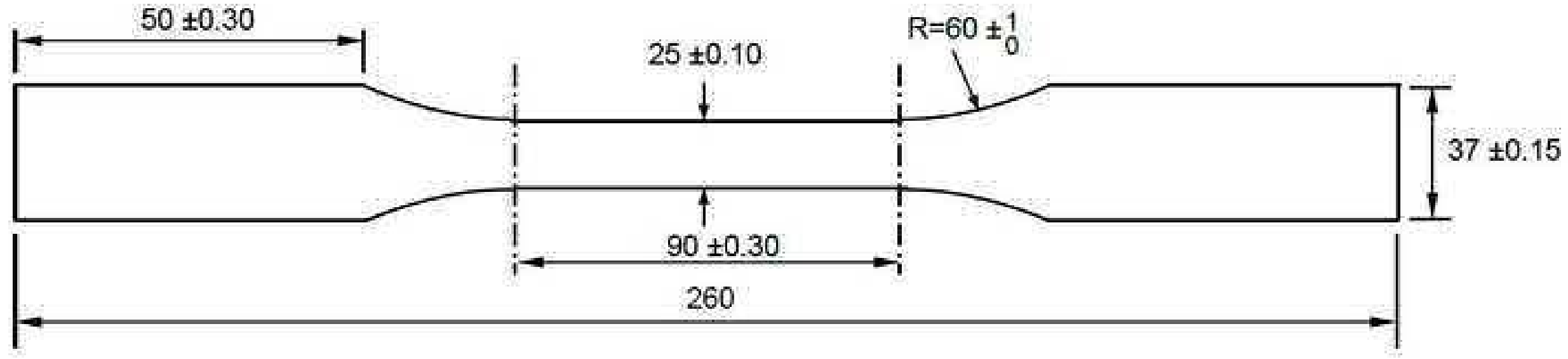


Figure 3
Click here to download high resolution image

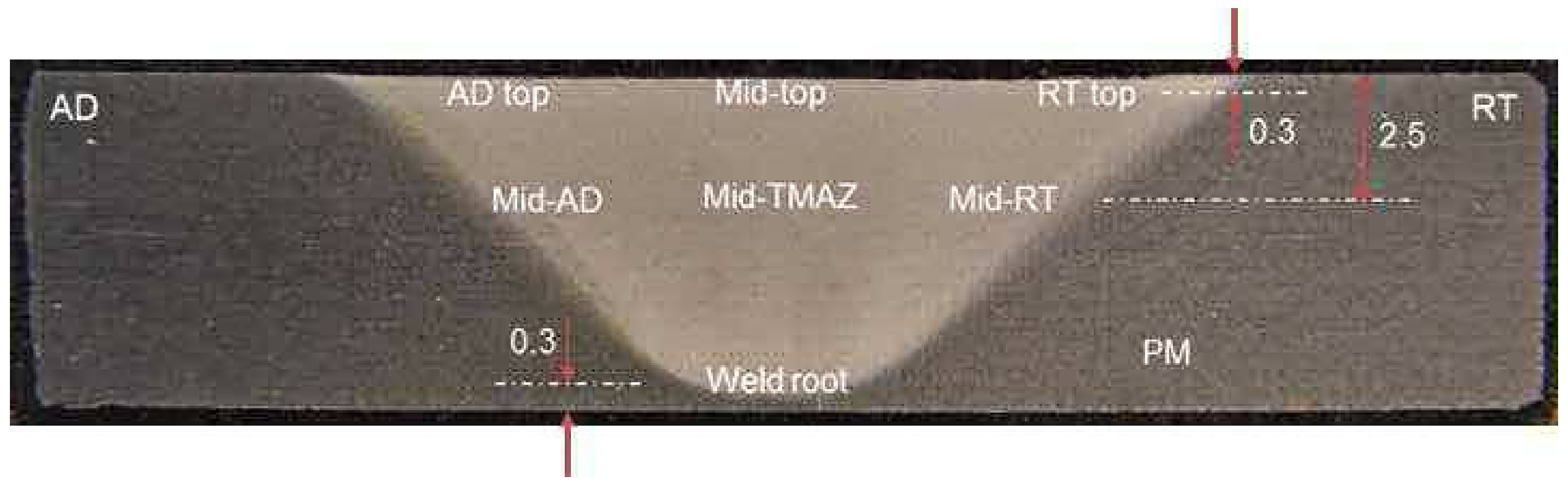


Click here to download high resolution image

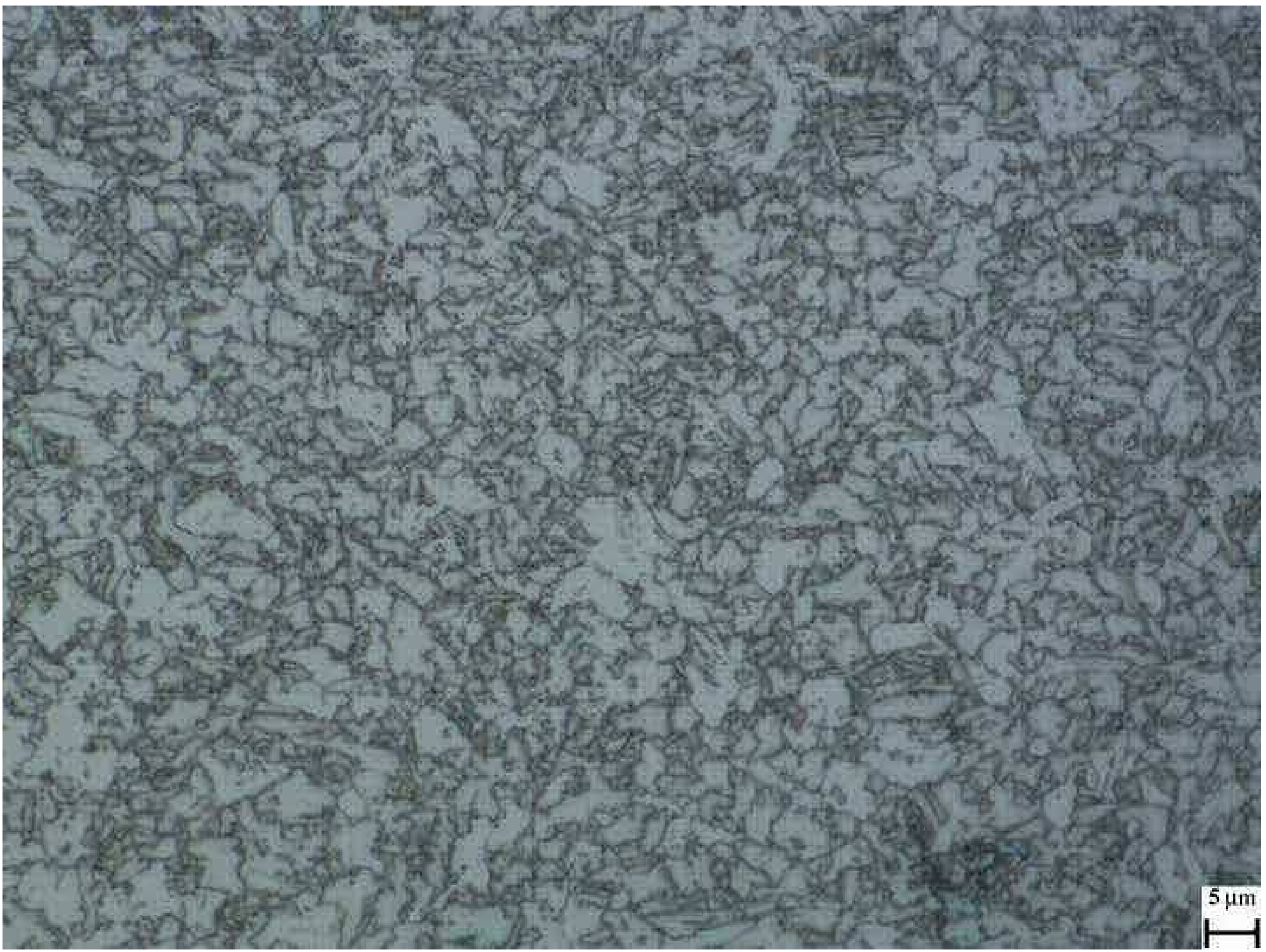




\section{Figure 5 \\ Click here to download high resolution image}

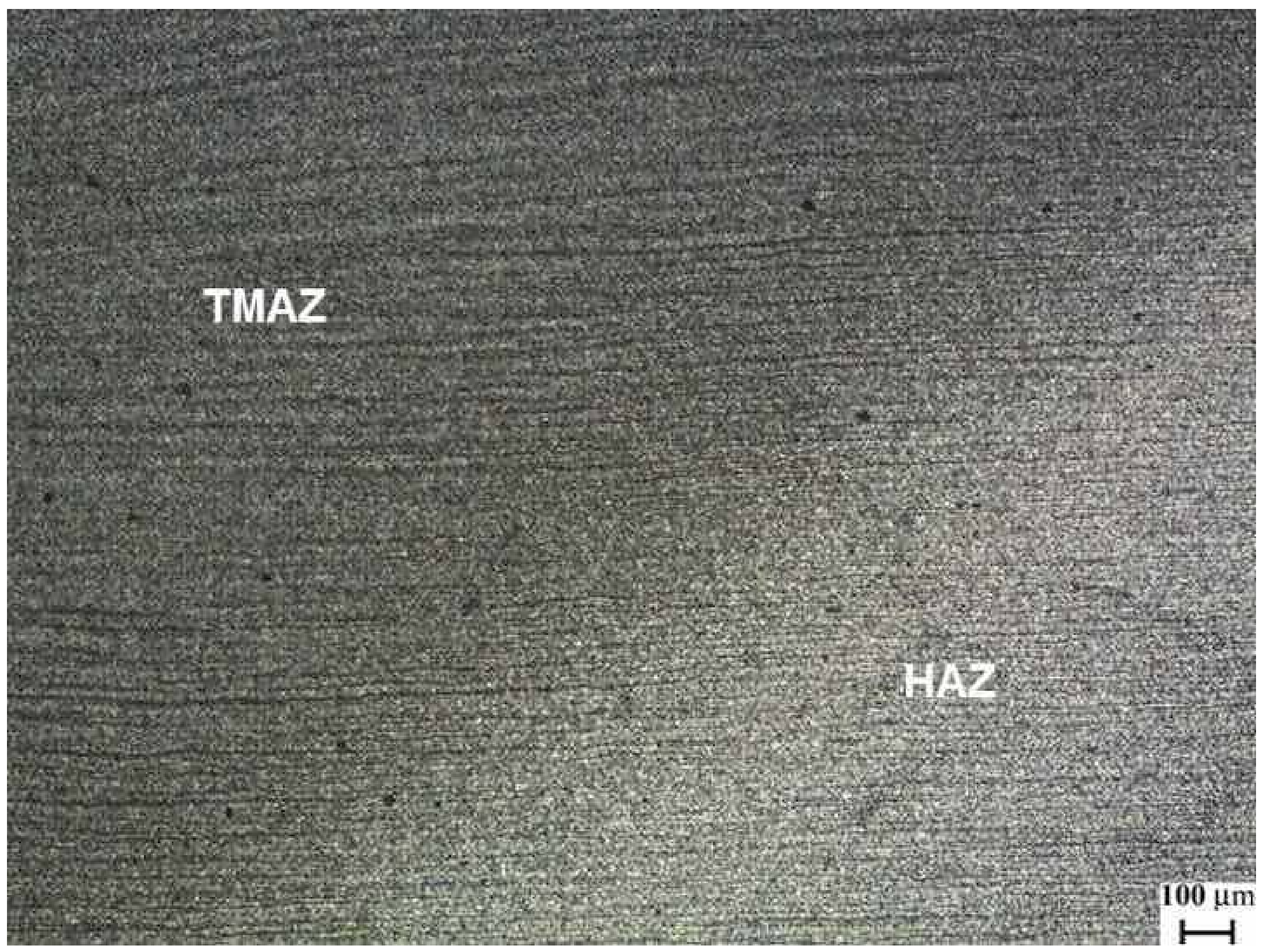

\section{TMAZ}




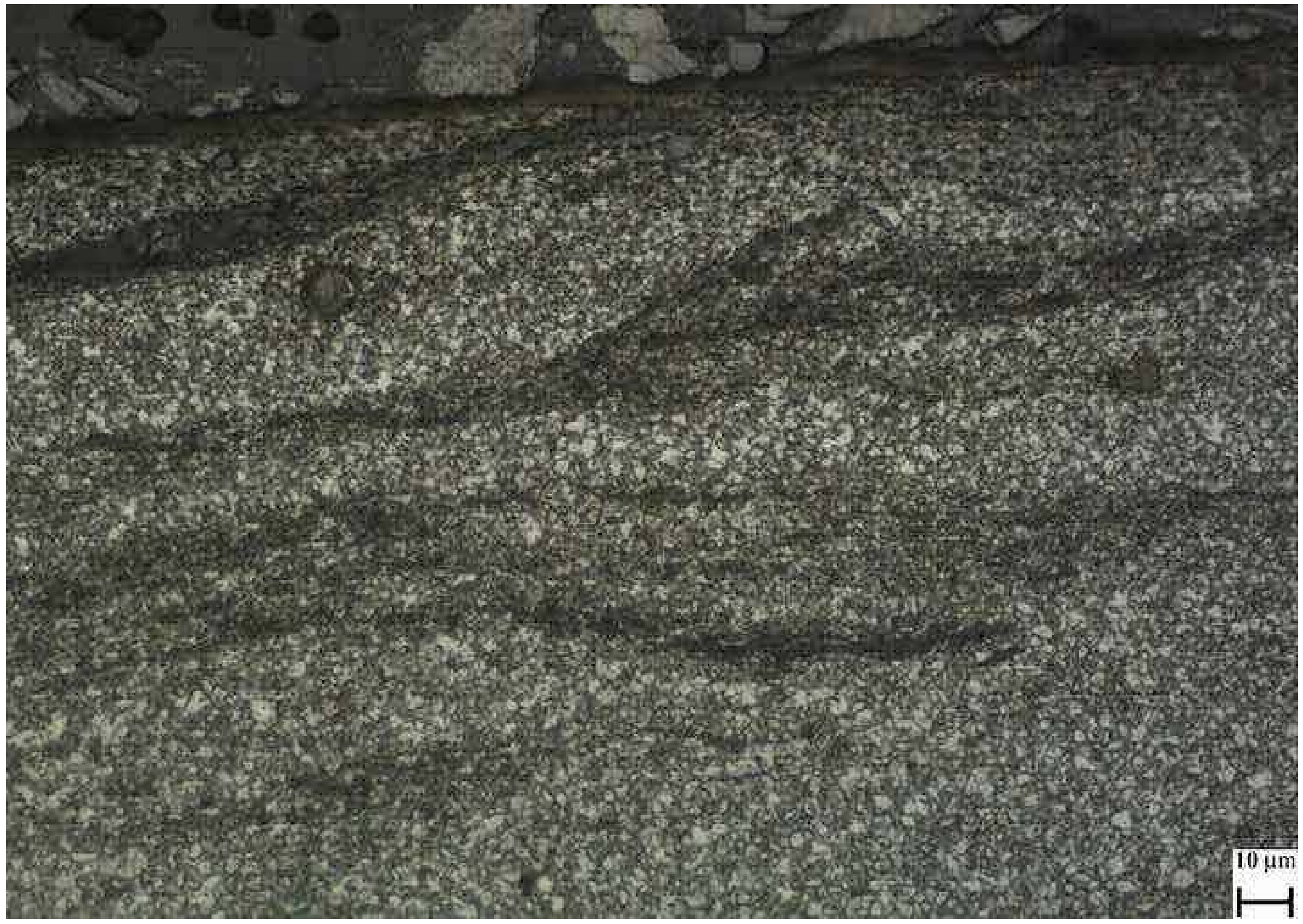


Click here to download high resolution image

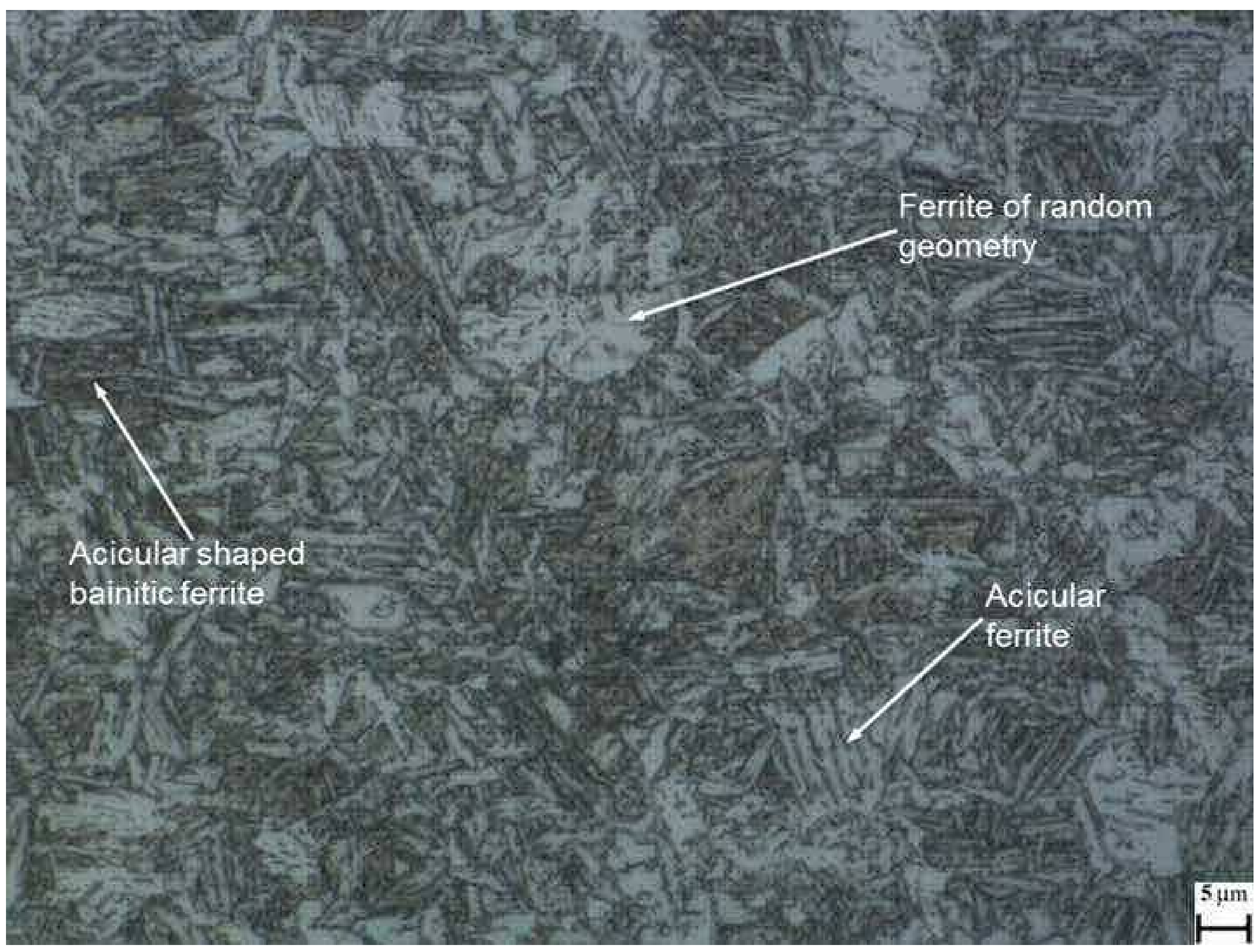

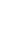


Figure $6 \mathrm{~b}$
Click here to download high resolution image

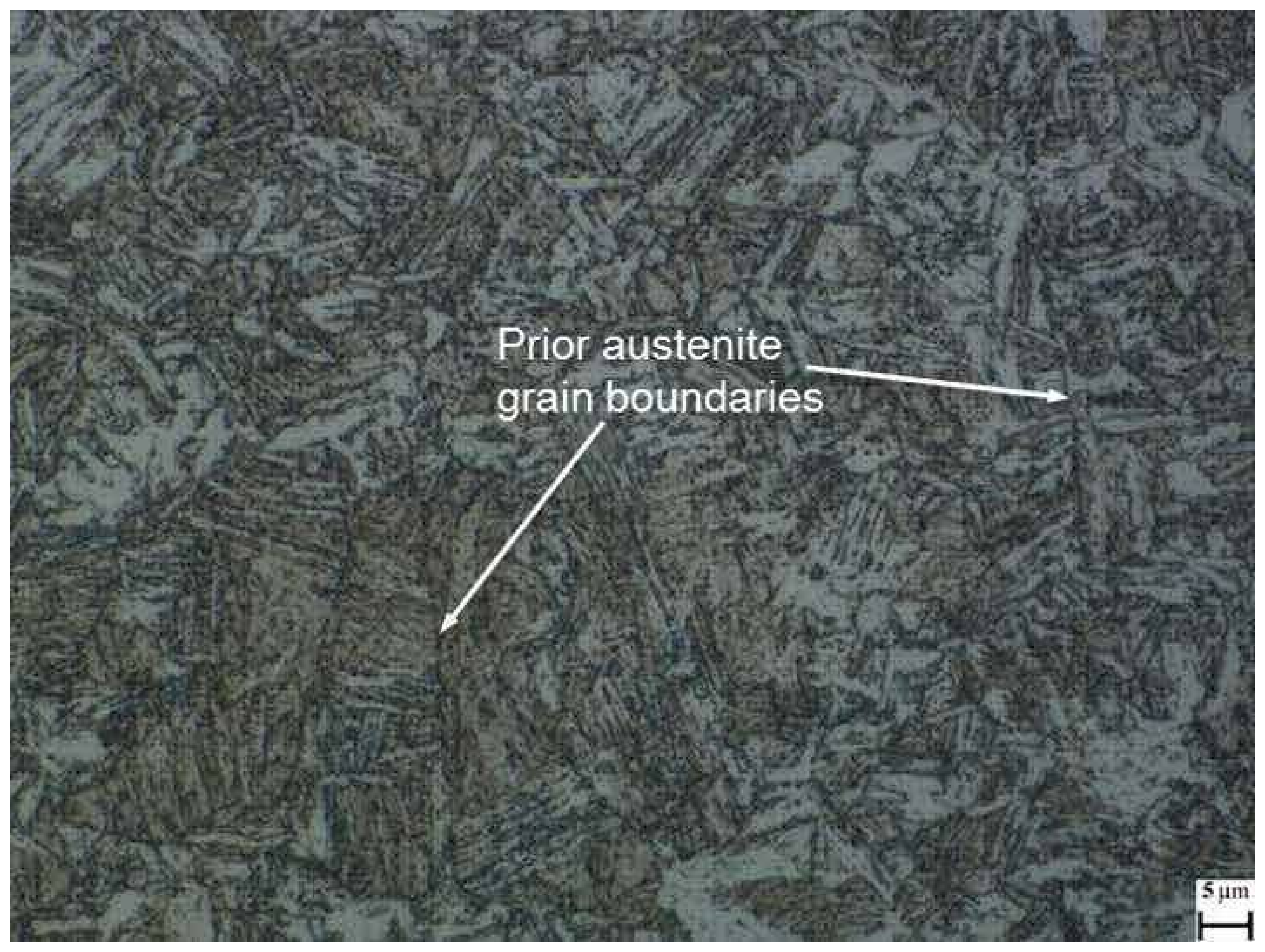


Click here to download high resolution image

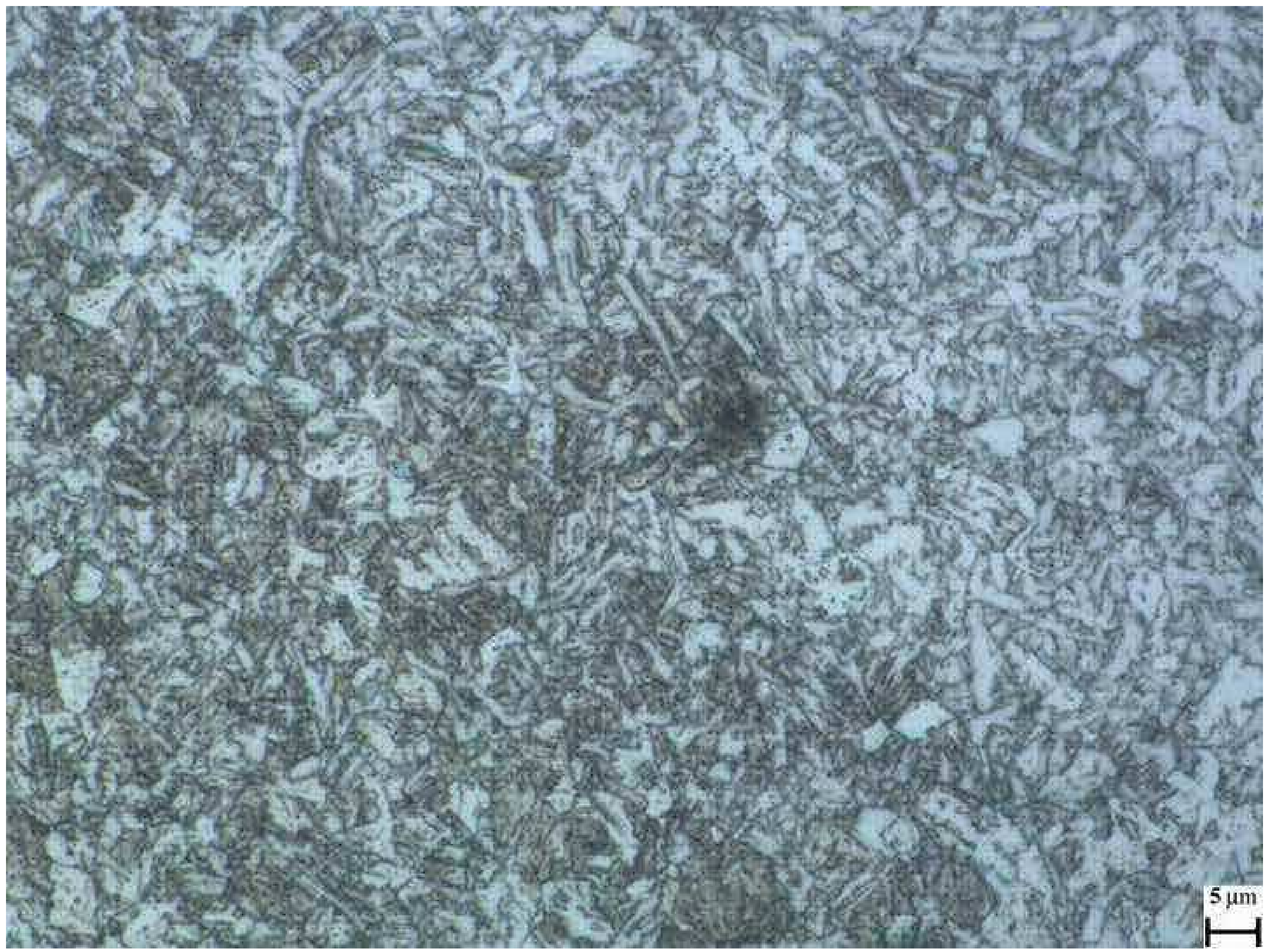




\section{Figure 7a \\ Click here to download high resolution image}

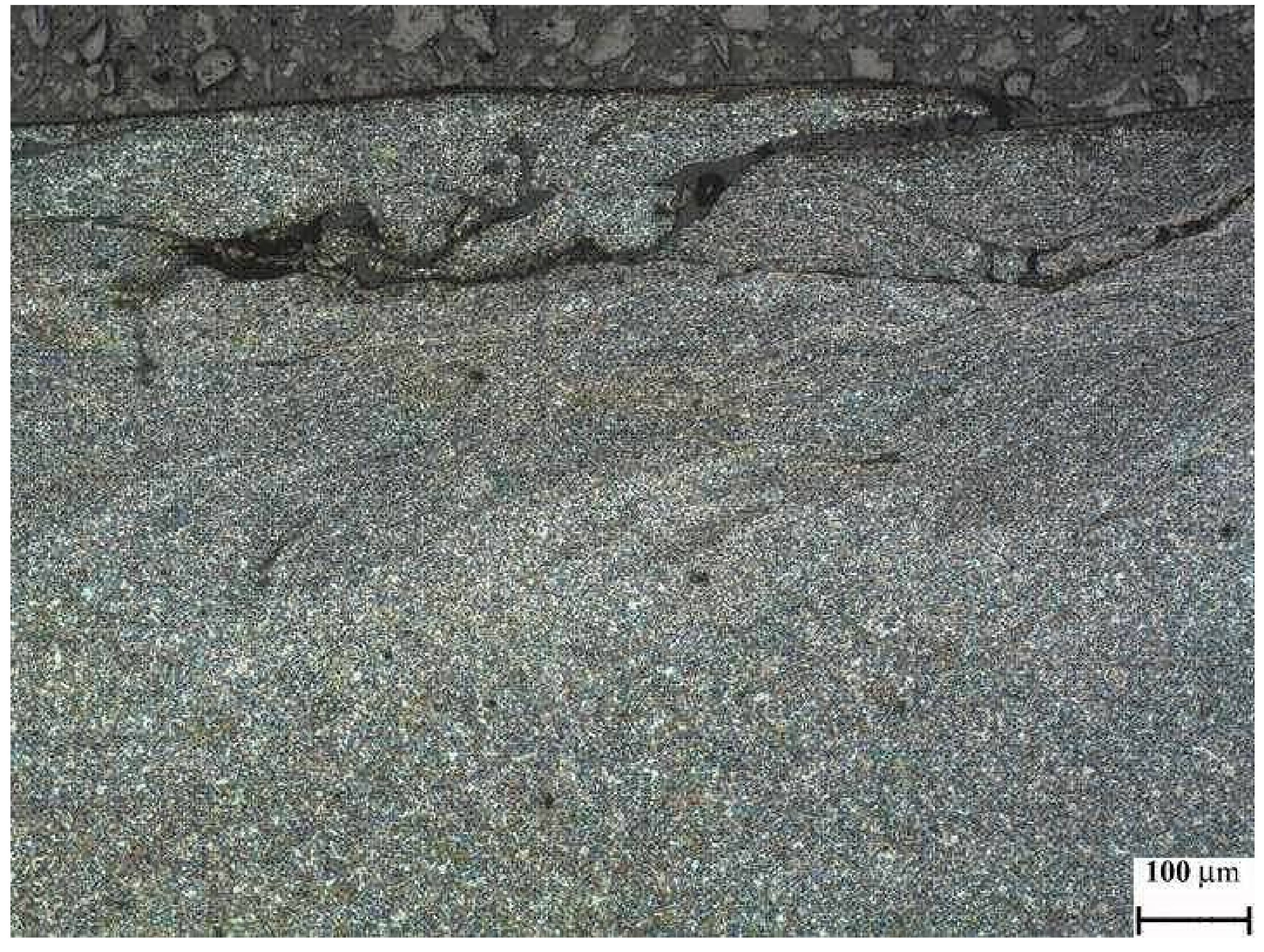




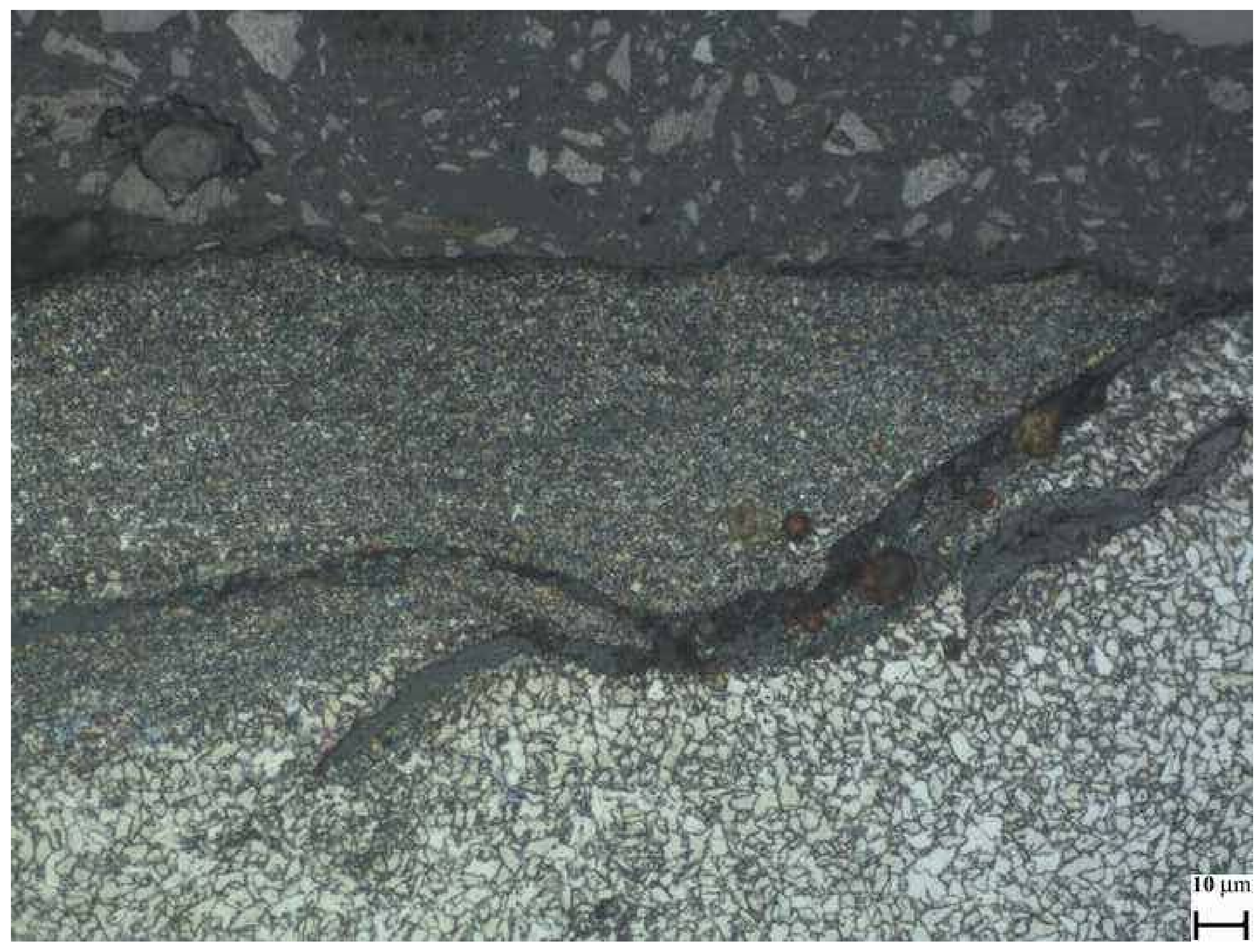

\section{Figure $7 \mathrm{~b}$ \\ Click here to download high resolution image}


Click here to download high resolution image

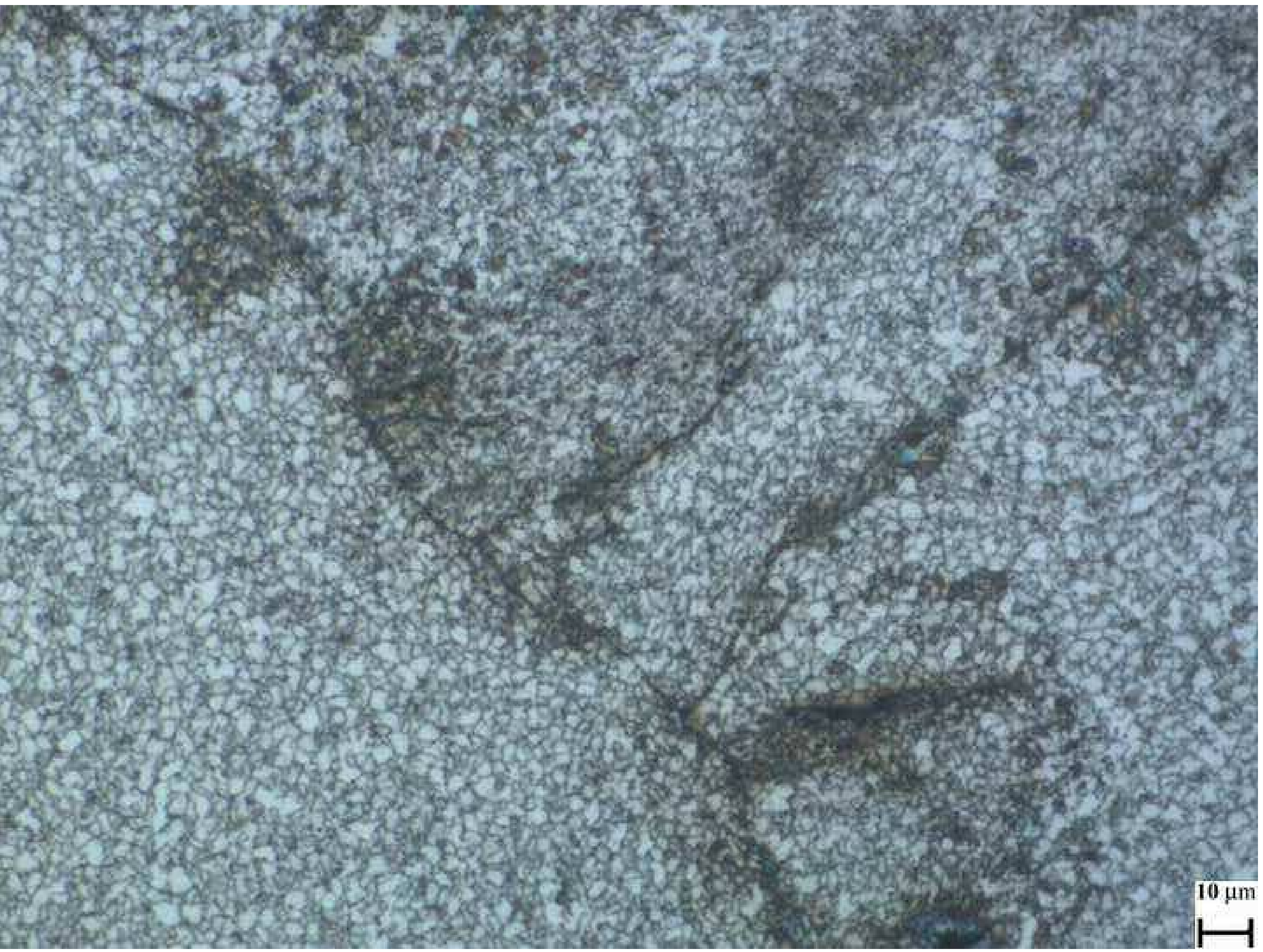


Click here to download high resolution image

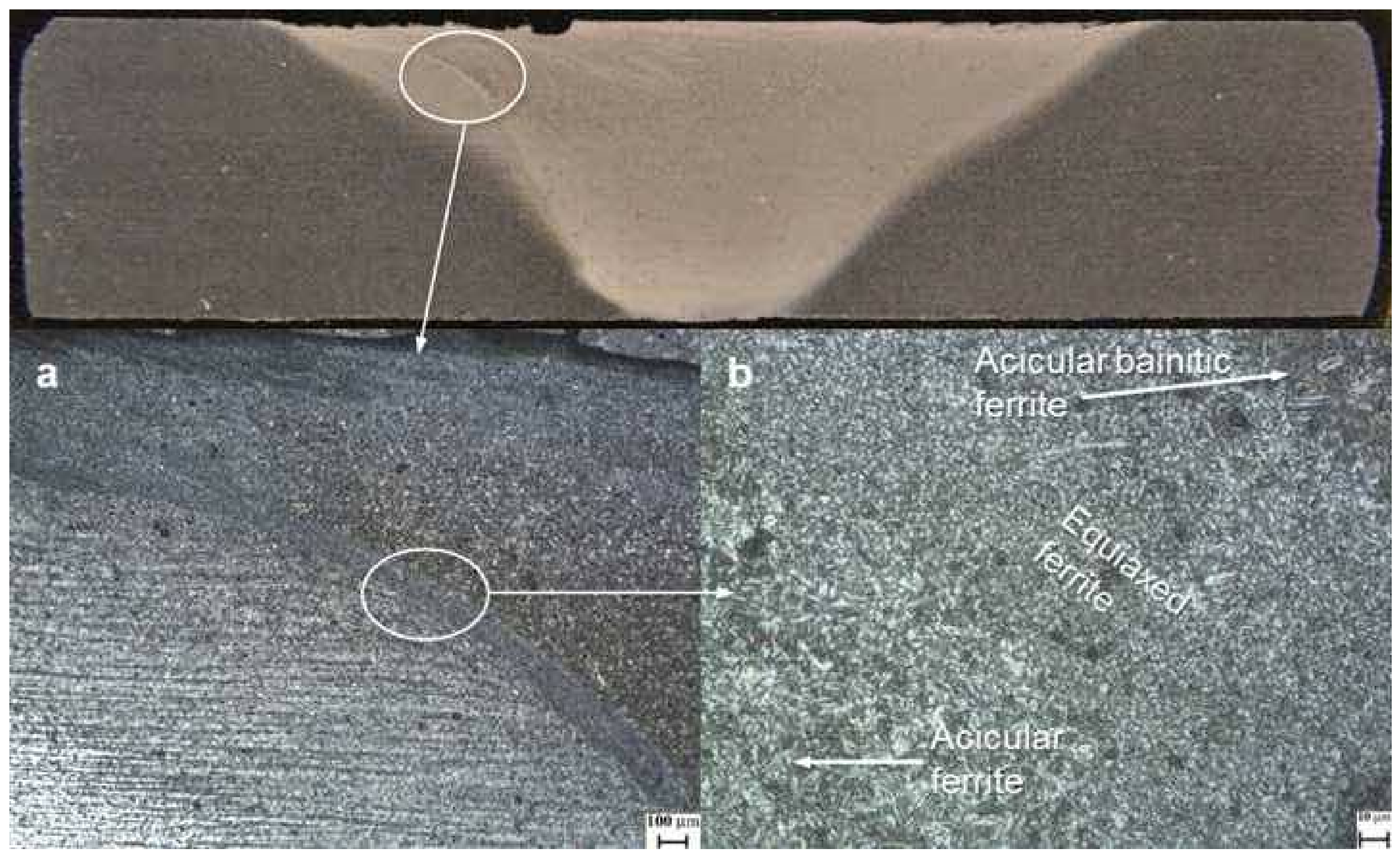




\section{igure 10 \\ Click here to download high resolution image}

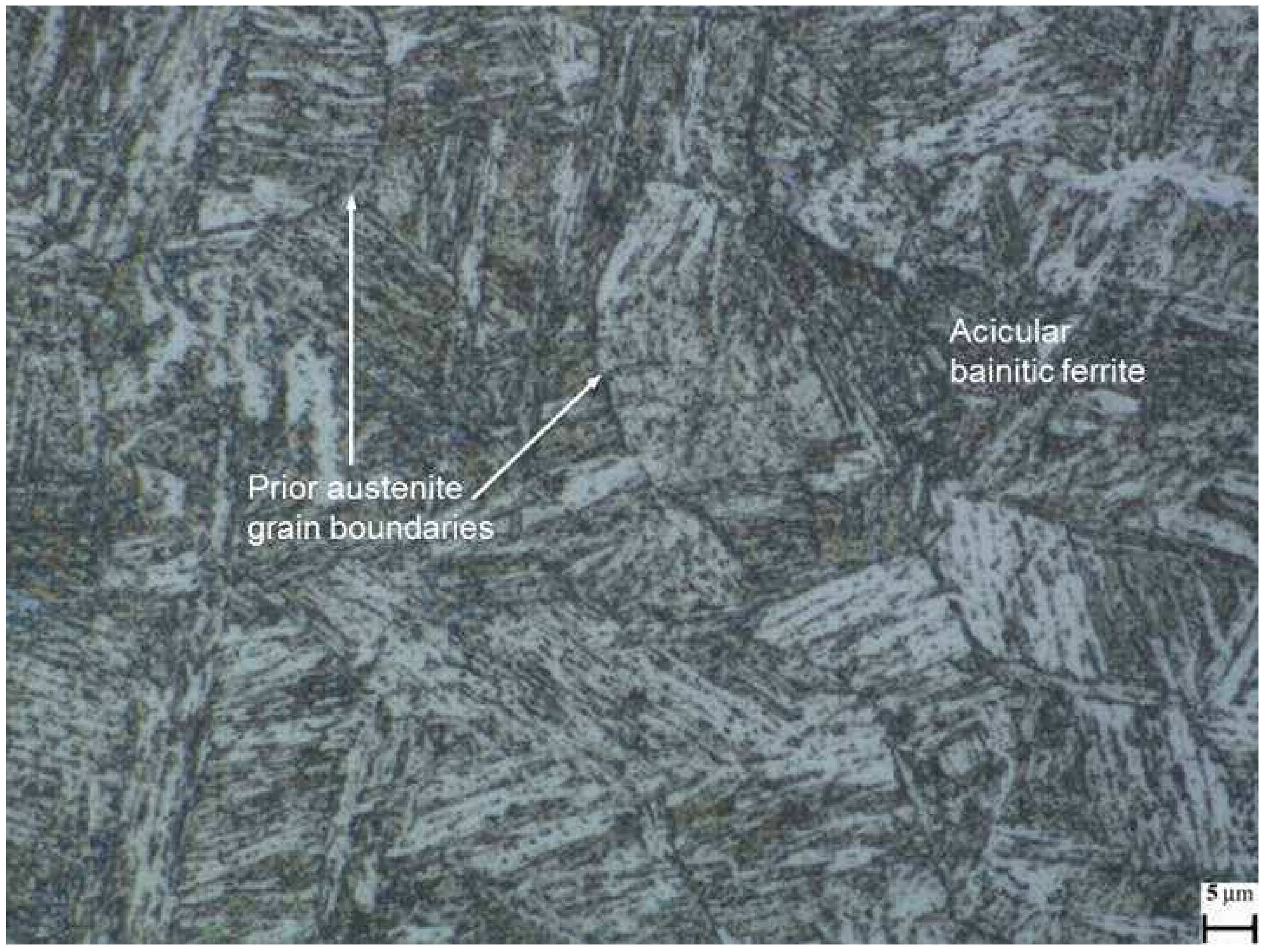




\section{Figure $11 a$ \\ Click here to download high resolution image}

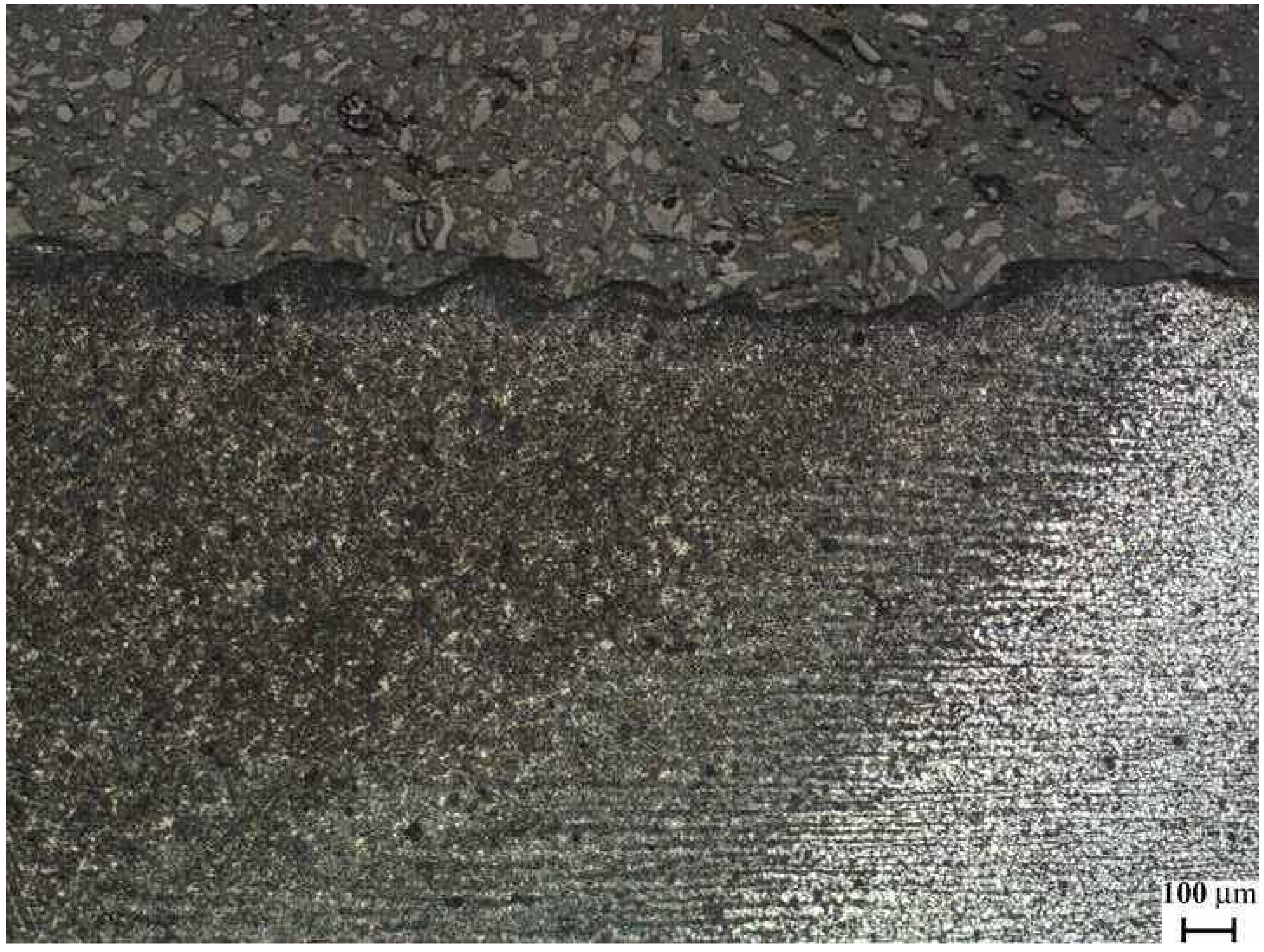


Click here to download high resolution image

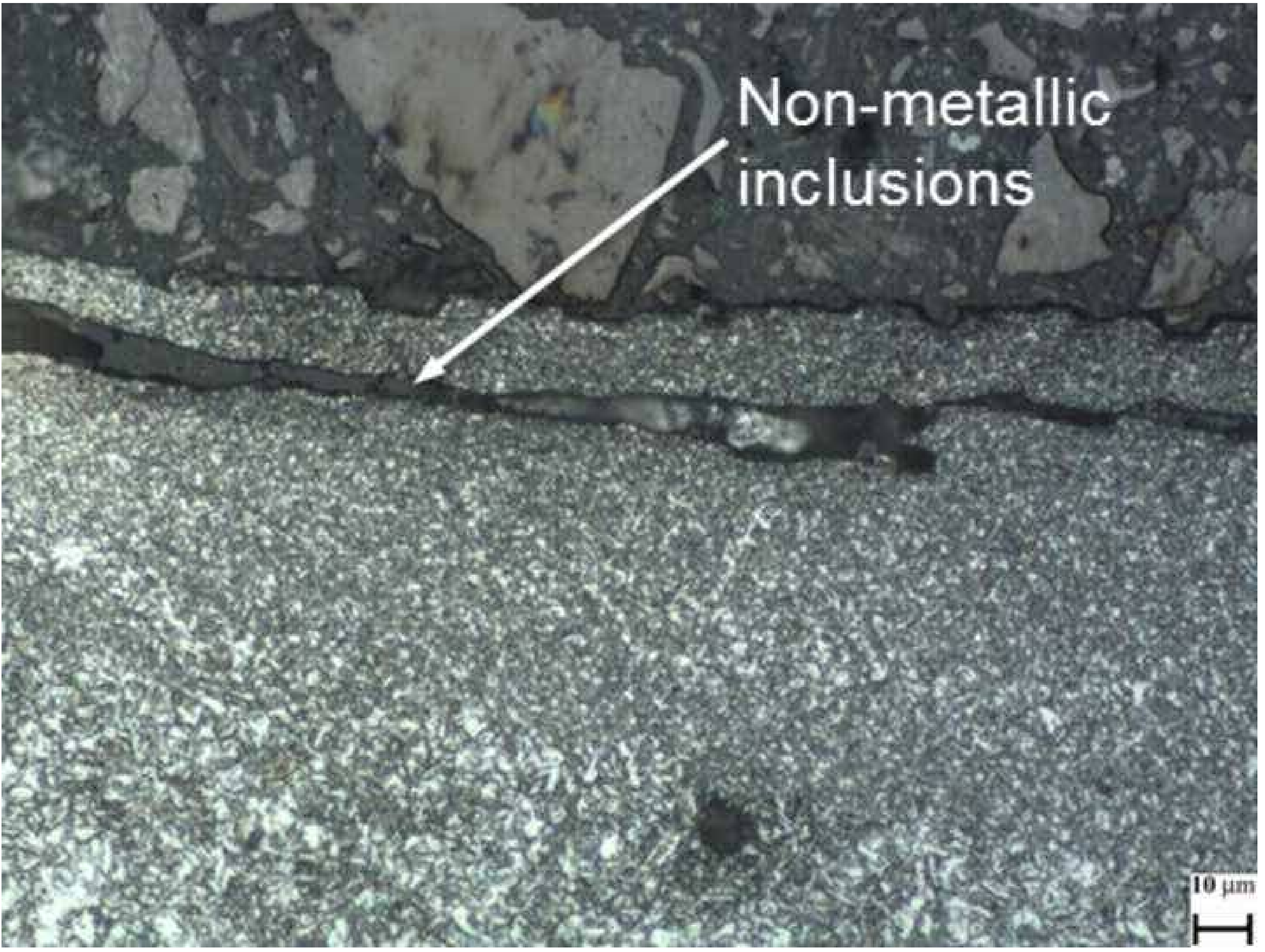


Click here to download high resolution image

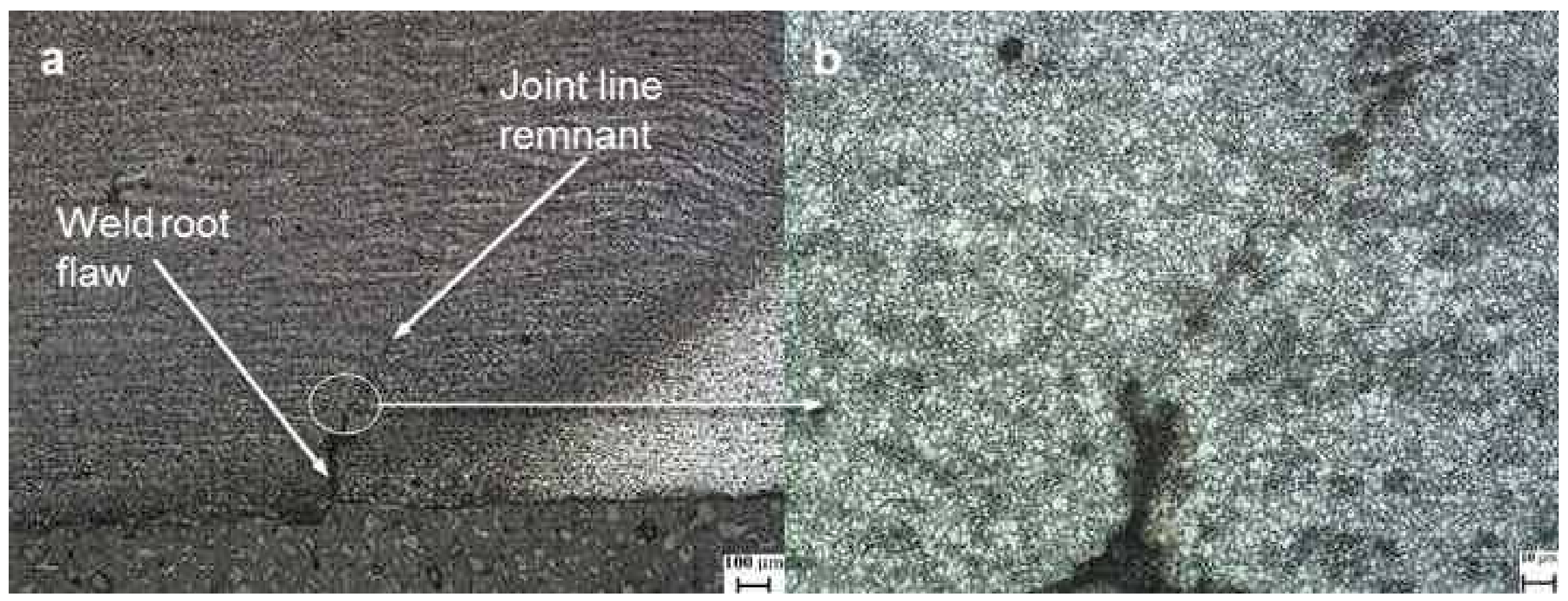




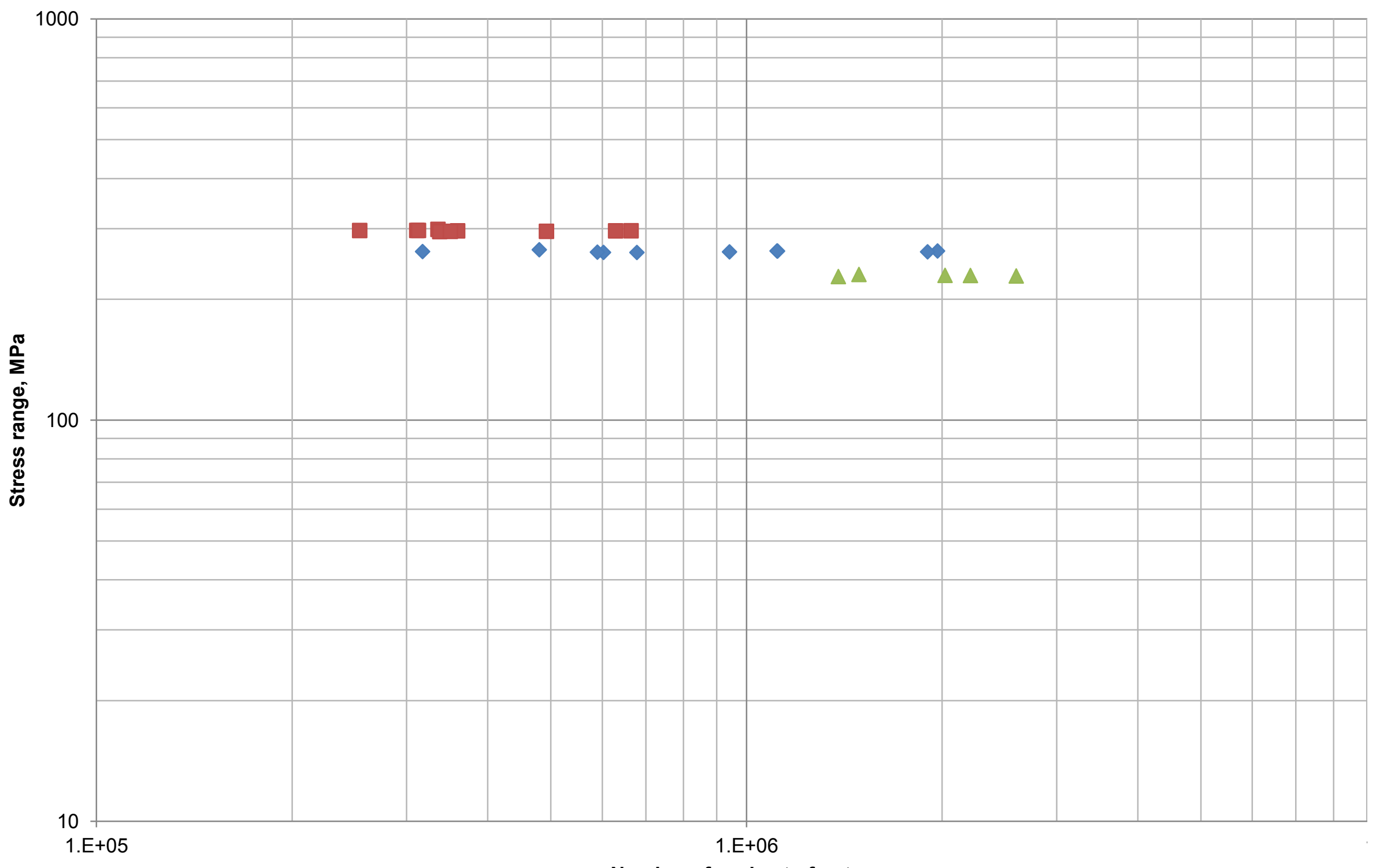

Number of cycles to fracture

$\triangle 70 \%$ of $Y S \quad 80 \%$ of $Y S \quad-90 \%$ of $Y S$ 


\section{Figure 14}

Click here to download high resolution image

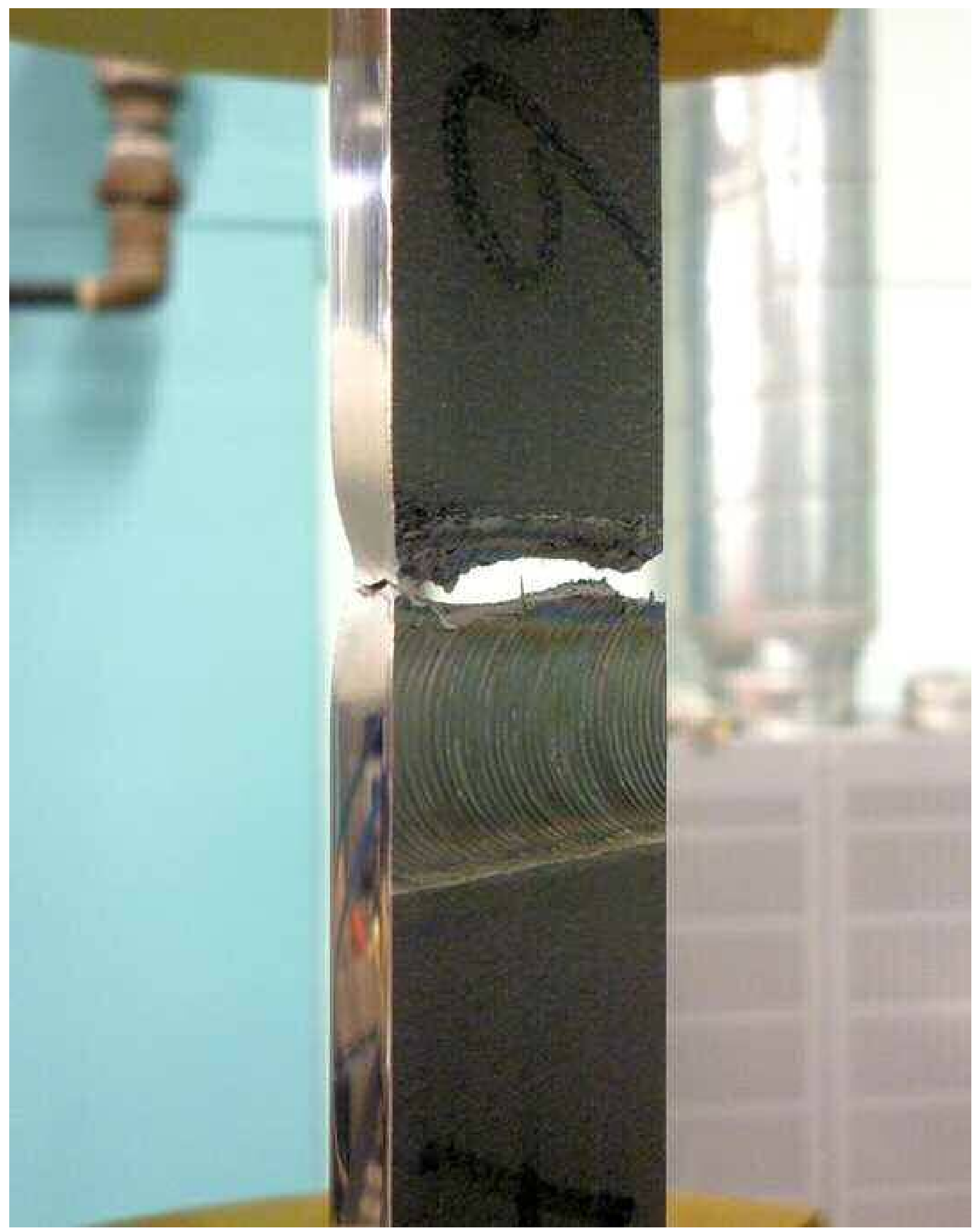




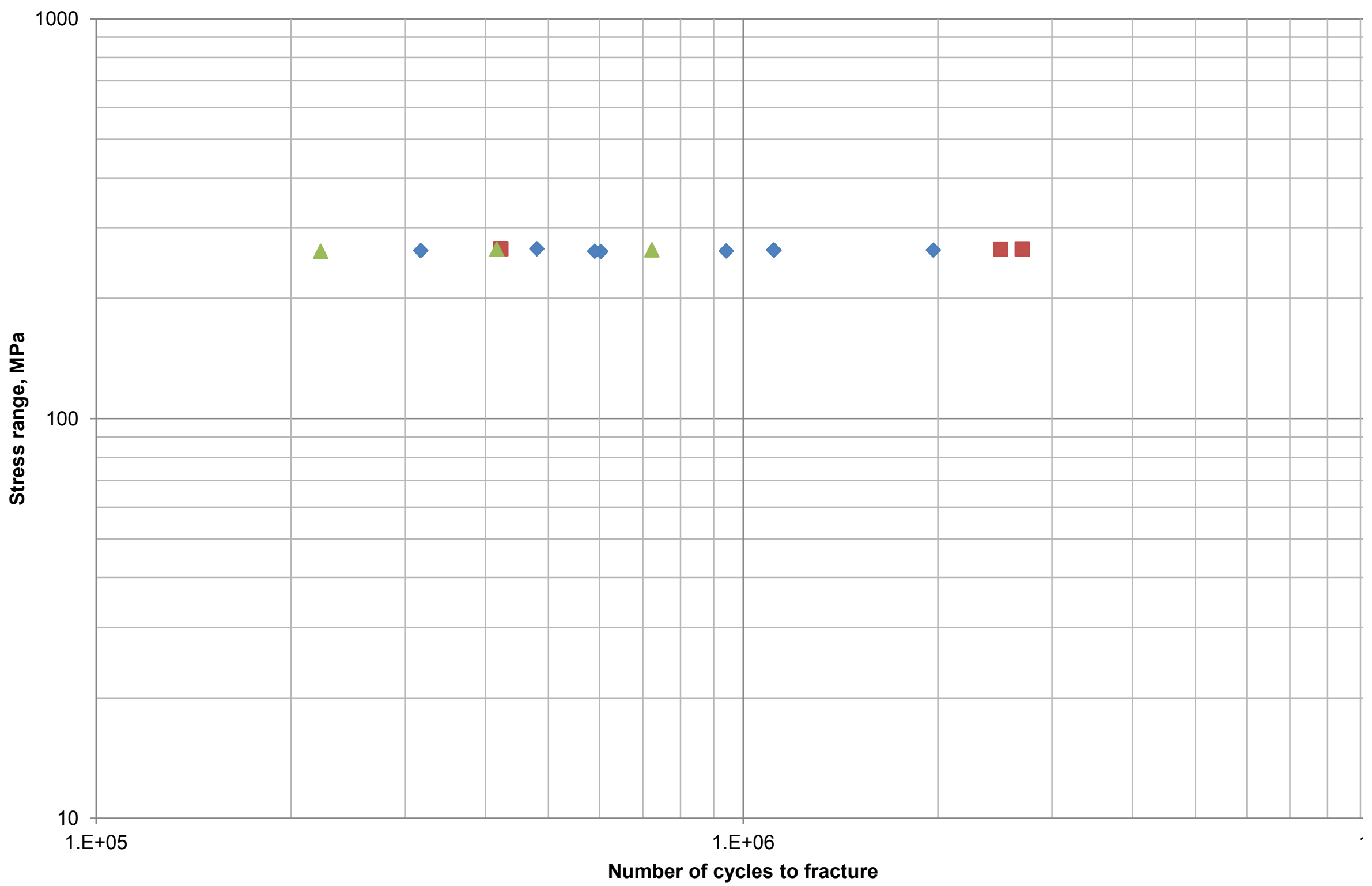

- Slow weld $\diamond$ Intermediate weld $\triangle$ Fast weld 


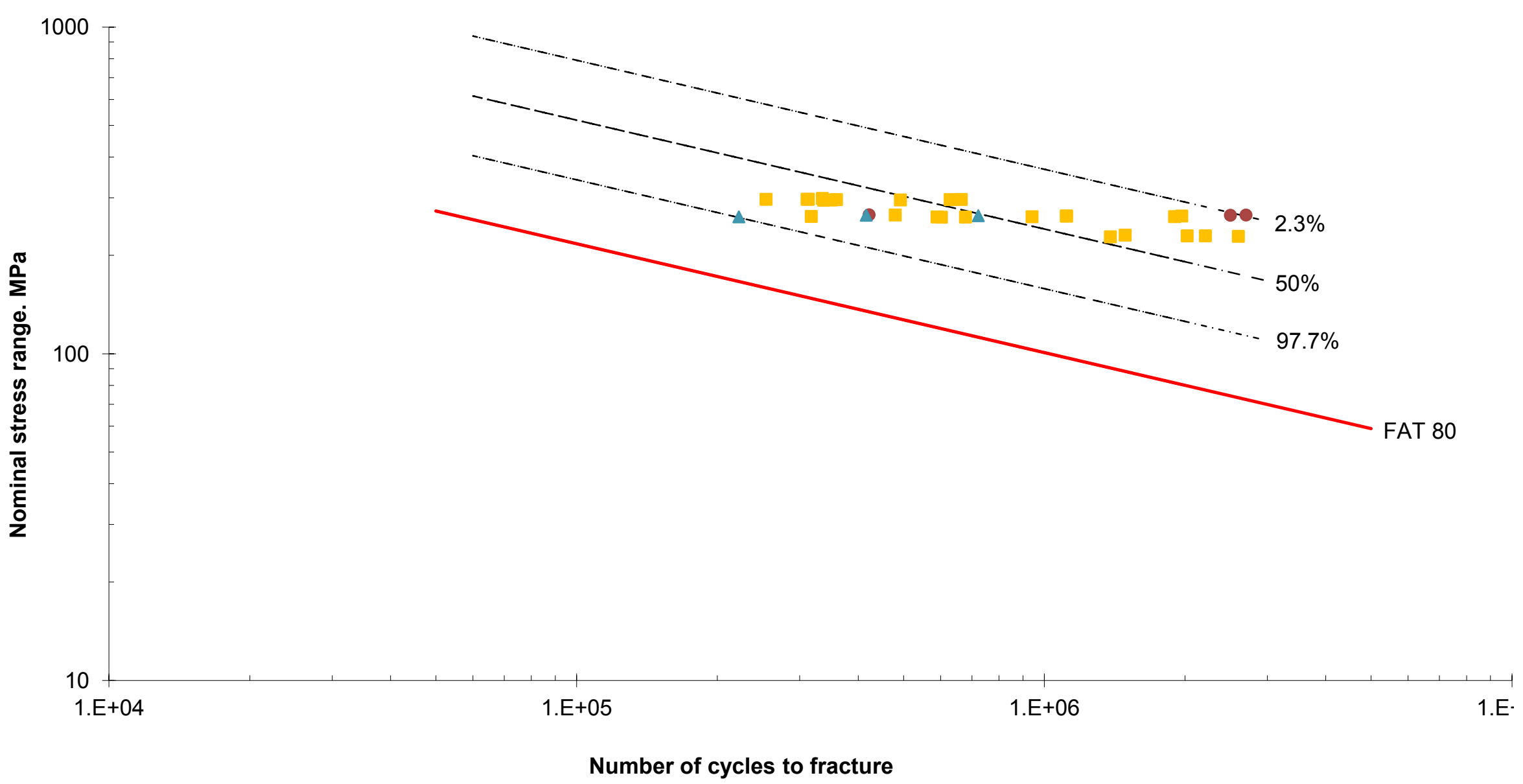

—FAT 80, $\mathrm{m}=3$ - Slow Intermediate $\quad$ Fast 


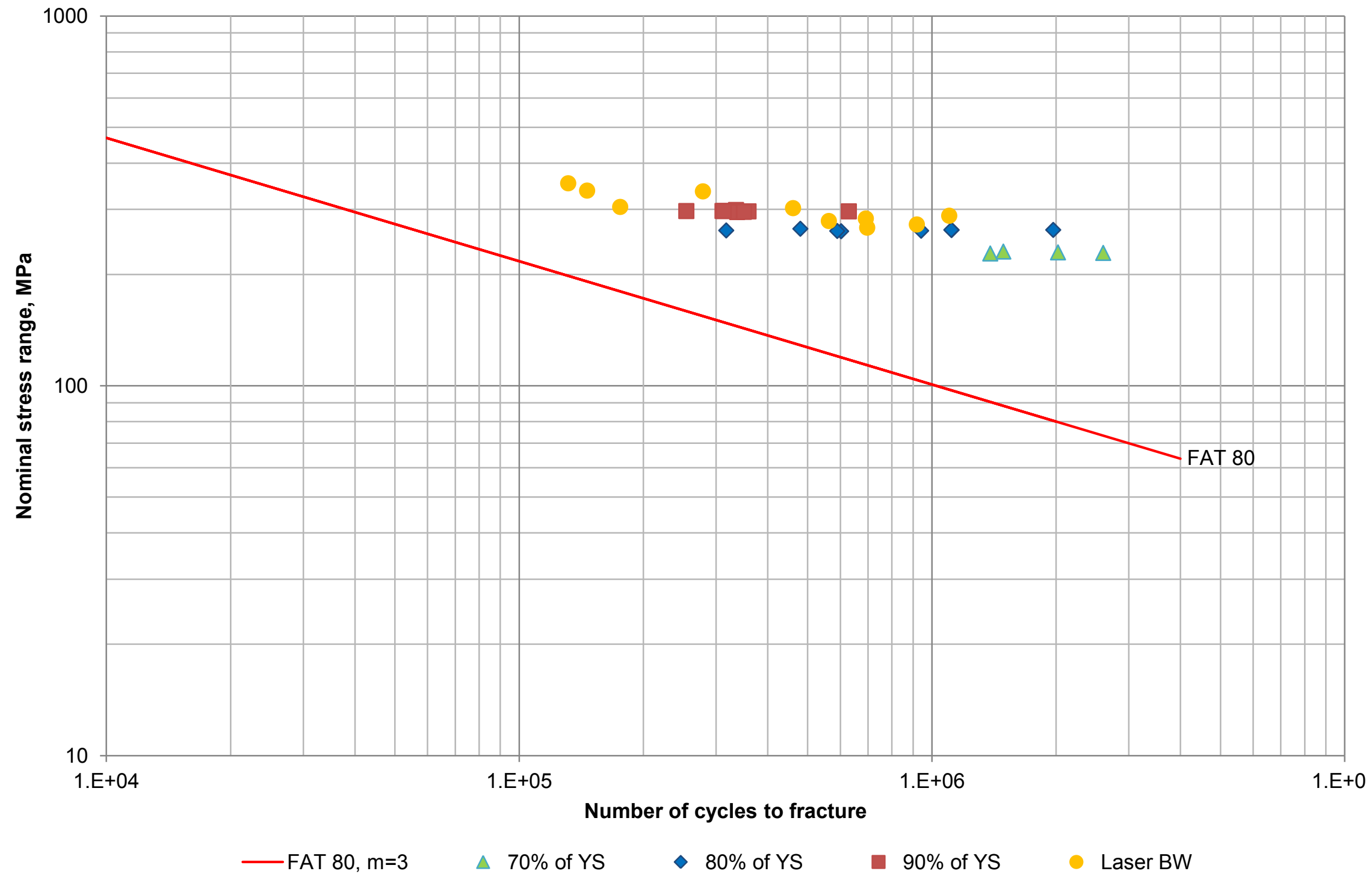




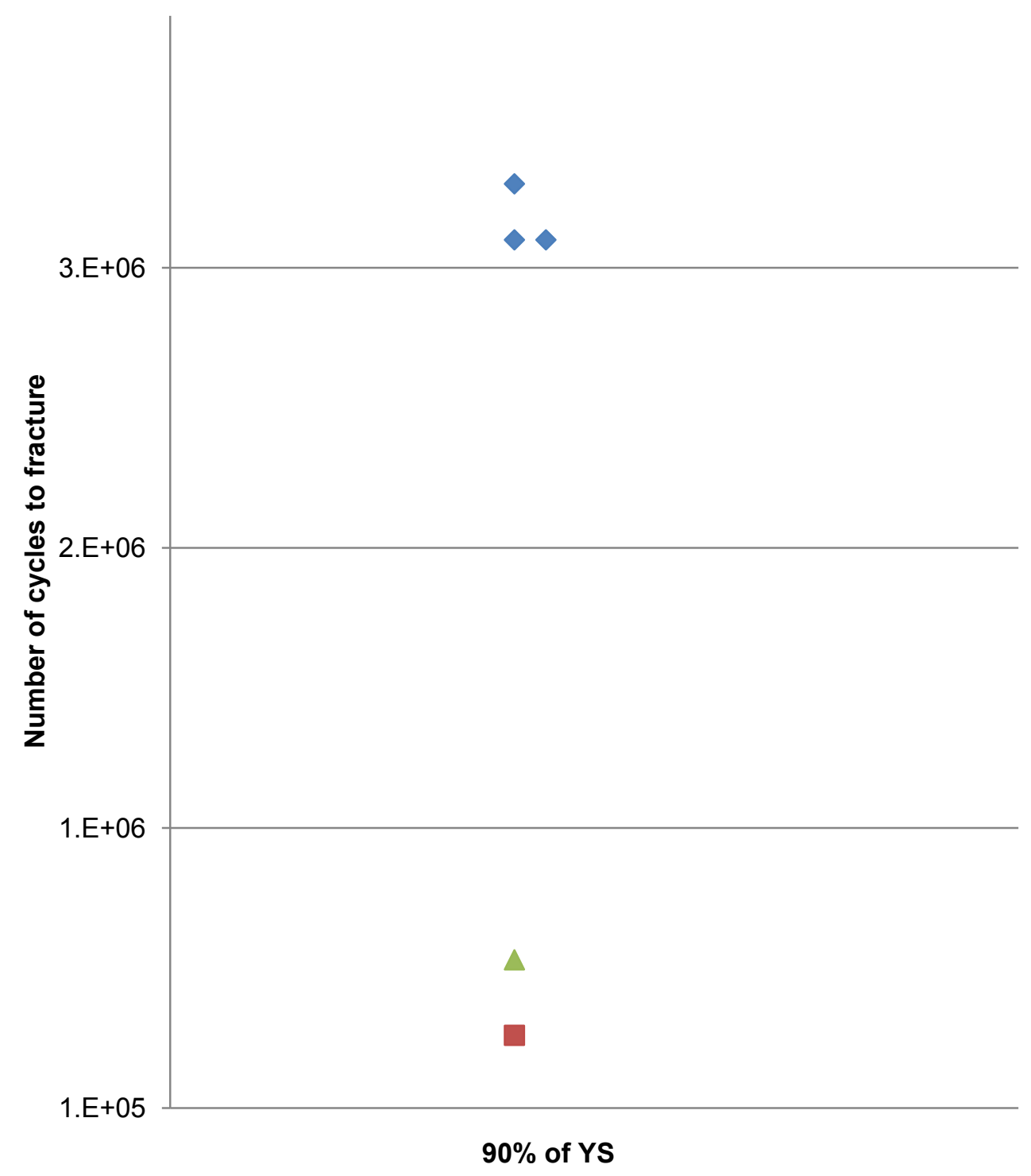

- Top $0.5 \mathrm{~mm}$

removed

-Test 4

$\triangle$ Test 8 
Click here to download high resolution image
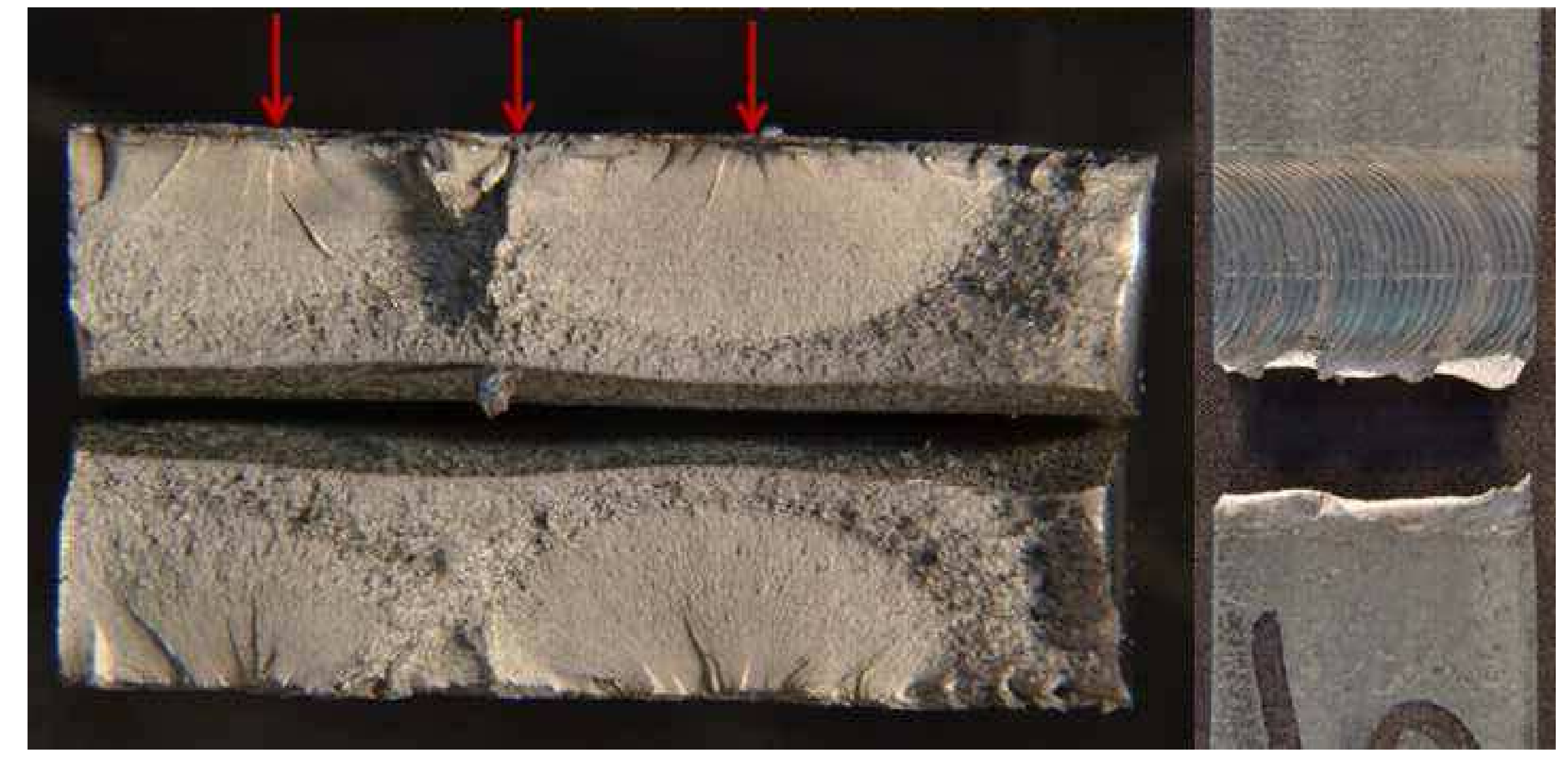
Click here to download high resolution image

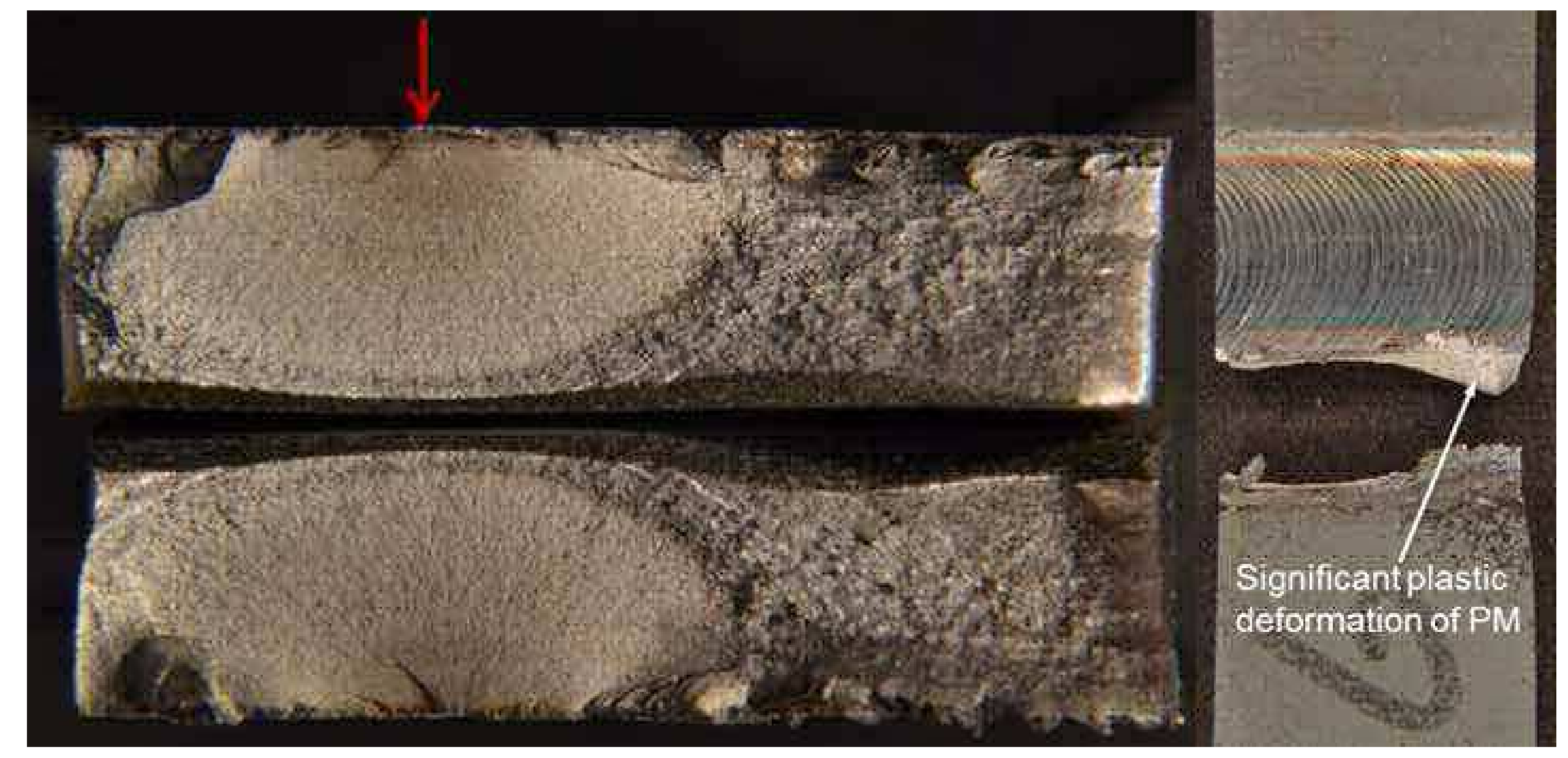




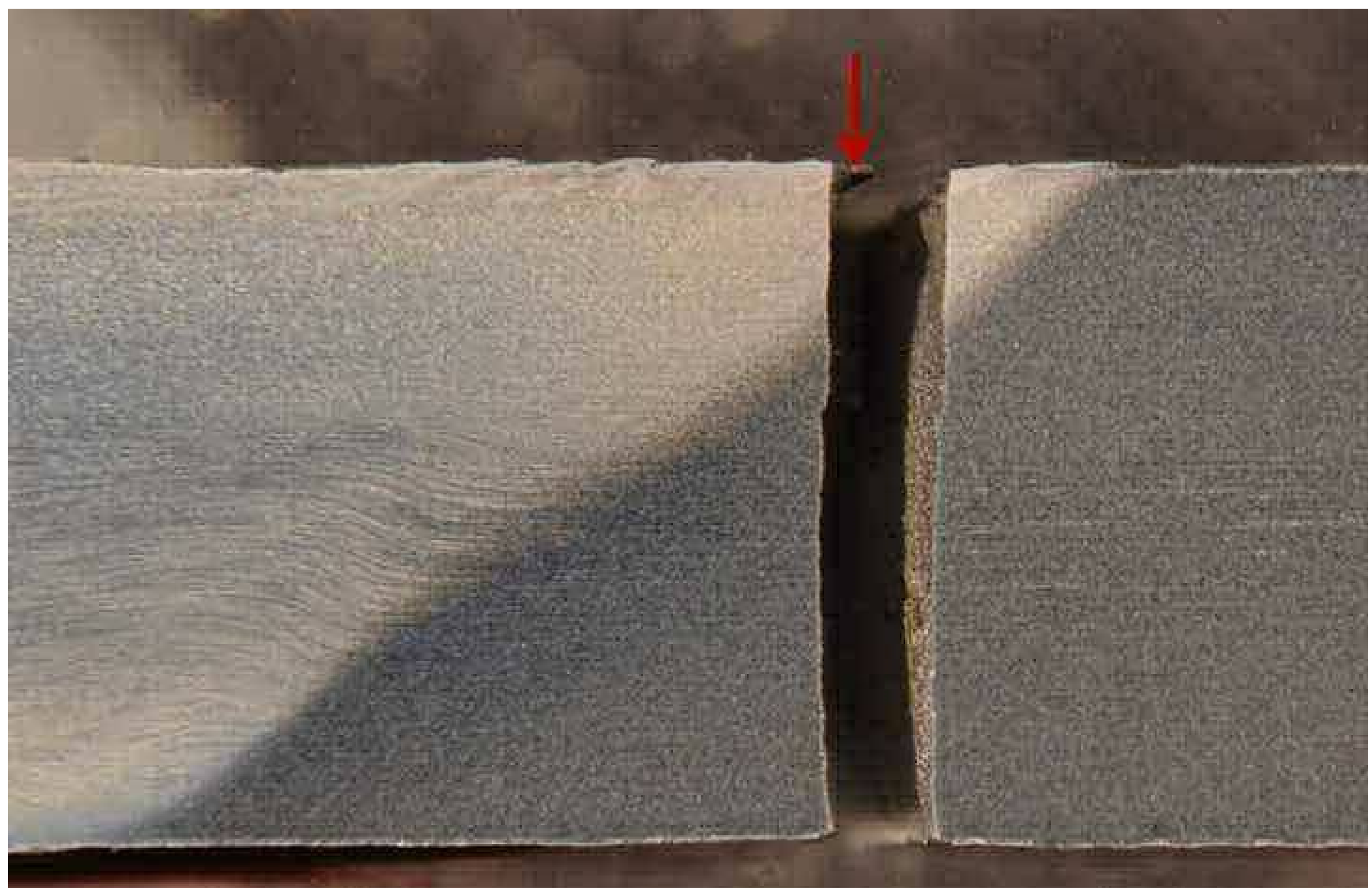




\section{Click here to download high resolution image}

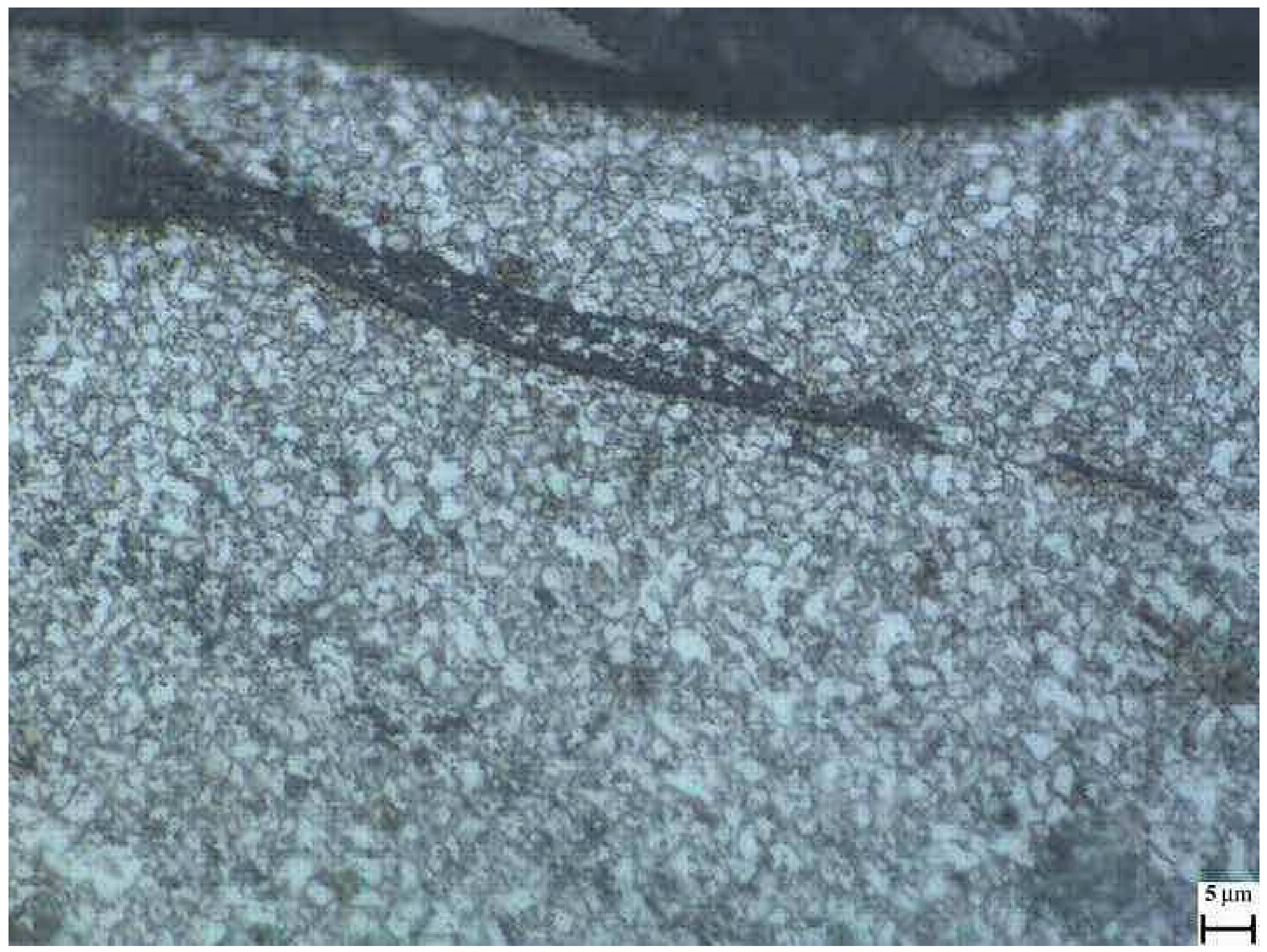

Sos dive

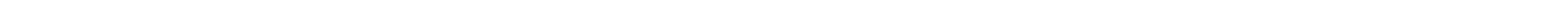

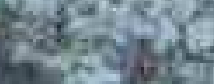

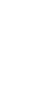


Figure 22

Click here to download high resolution image

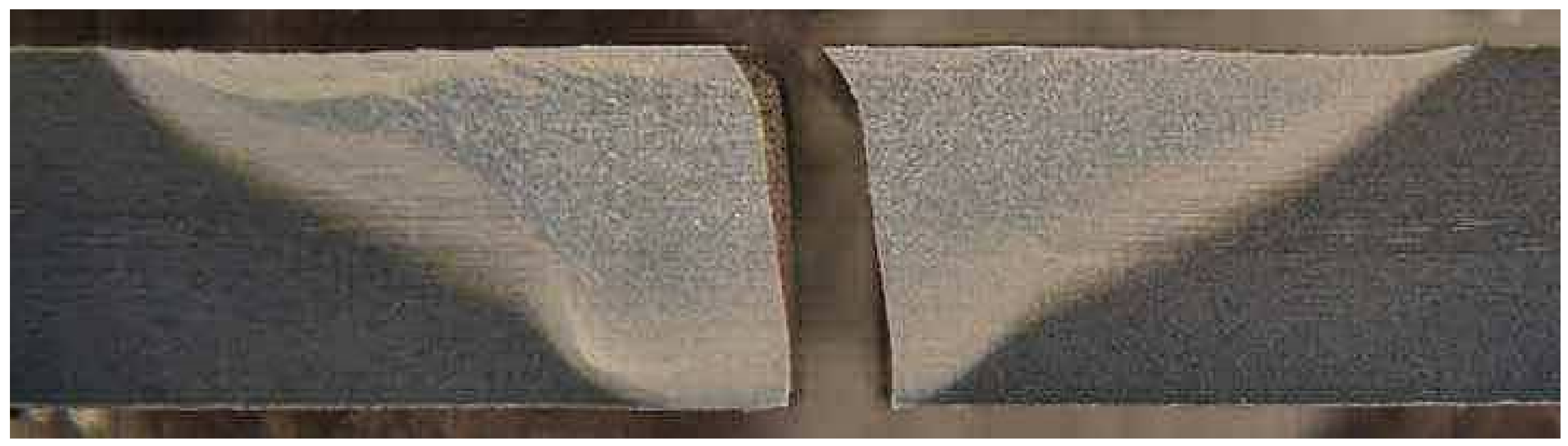


Figure 23
Click here to download high resolution image

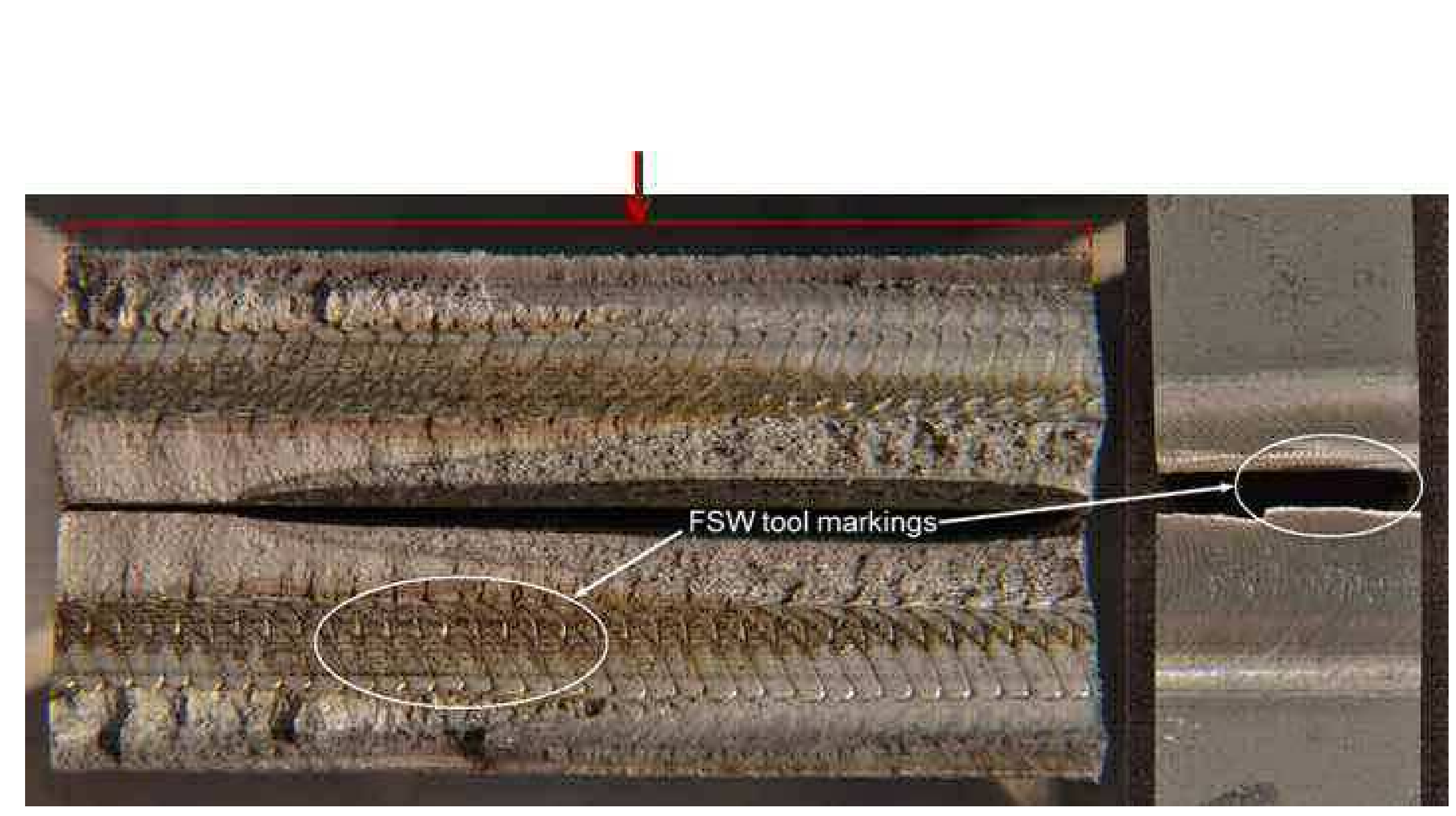

